\title{
Effect of Intake Air Filter Condition on Vehicle Fuel Economy
}

February 2009

Prepared by

Kevin Norman

Shean Huff

Brian West

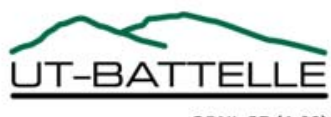




\title{
DOCUMENT AVAILABILITY
}

Reports produced after January 1, 1996, are generally available free via the U.S. Department of Energy (DOE) Information Bridge.

Web site http://www.osti.gov/bridge

Reports produced before January 1, 1996, may be purchased by members of the public from the following source.

\author{
National Technical Information Service \\ 5285 Port Royal Road \\ Springfield, VA 22161 \\ Telephone 703-605-6000 (1-800-553-6847) \\ TDD 703-487-4639 \\ Fax 703-605-6900 \\ E-mail info@ntis.gov \\ Web site http://www.ntis.gov/support/ordernowabout.htm
}

Reports are available to DOE employees, DOE contractors, Energy Technology Data Exchange (ETDE) representatives, and International Nuclear Information System (INIS) representatives from the following source.

Office of Scientific and Technical Information

P.O. Box 62

Oak Ridge, TN 37831

Telephone 865-576-8401

Fax 865-576-5728

E-mail reports@osti.gov

Web site http://www.osti.gov/contact.html

This report was prepared as an account of work sponsored by an agency of the United States Government. Neither the United States Government nor any agency thereof, nor any of their employees, makes any warranty, express or implied, or assumes any legal liability or responsibility for the accuracy, completeness, or usefulness of any information, apparatus, product, or process disclosed, or represents that its use would not infringe privately owned rights. Reference herein to any specific commercial product, process, or service by trade name, trademark, manufacturer, or otherwise, does not necessarily constitute or imply its endorsement, recommendation, or favoring by the United States Government or any agency thereof. The views and opinions of authors expressed herein do not necessarily state or reflect those of the United States Government or any agency thereof. 
Energy and Transportation Science Division

\title{
EFFECT OF INTAKE AIR FILTER CONDITION ON VEHICLE FUEL ECONOMY
}

\author{
Kevin Norman \\ Shean Huff \\ Brian West
}

Date Published: February 2009

Prepared by OAK RIDGE NATIONAL LABORATORY

Oak Ridge, Tennessee 37831-6283

managed by

UT-BATTELLE, LLC

for the

U.S. DEPARTMENT OF ENERGY

under contract DE-AC05-00OR22725 



\section{CONTENTS}

Page

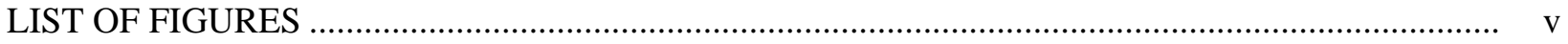

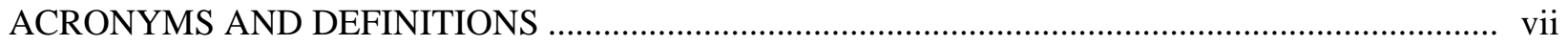

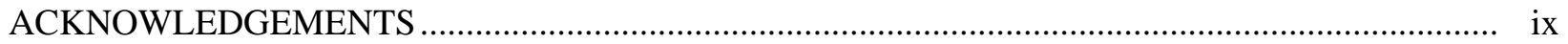

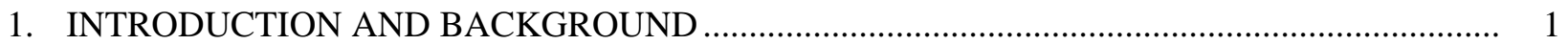

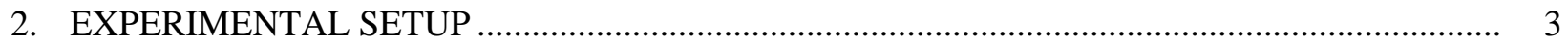

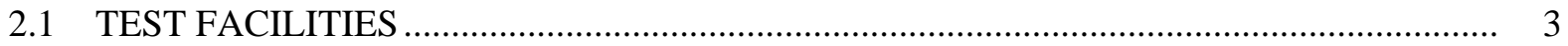

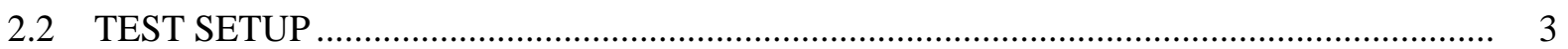

2.3 DEFINING A CLOGGED AIR FILTER ...................................................................... 5

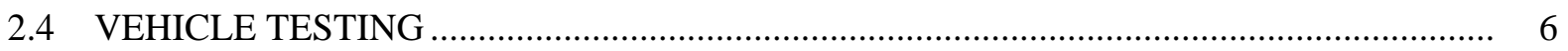

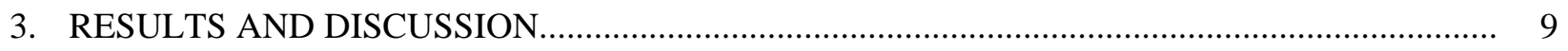

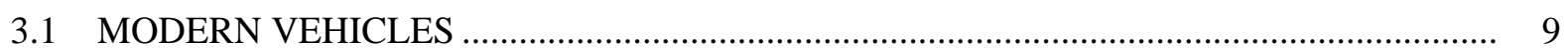

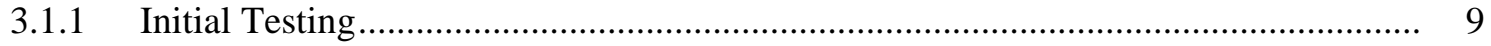

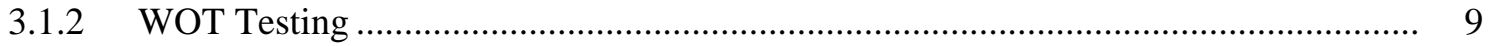

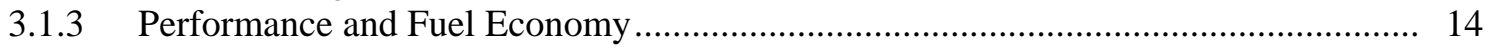

3.2 CARBURETED VEHICLE-1972 PONTIAC GRANDVILLE …....................................... 16

3.3 FURTHER INVESTIGATIONS-SIMULATING A SEVERELY

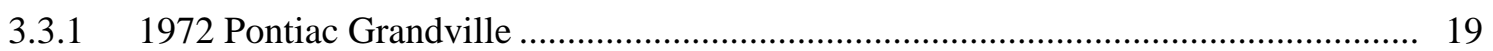

3.3.2 2007 Buick Lucerne.......................................................................................... 23

4. CONCLUSIONS AND FUTURE WORK.............................................................................. 25

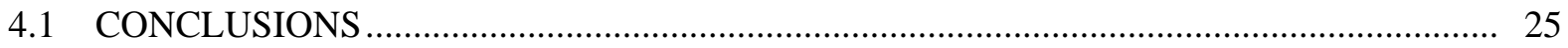

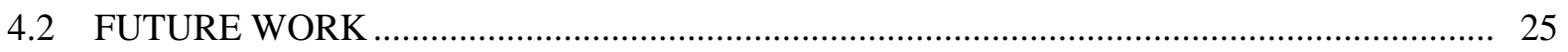

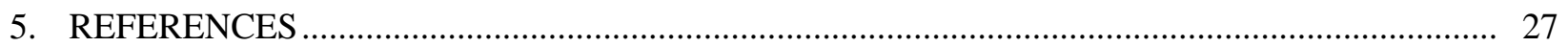





\section{LIST OF FIGURES}

Figure

2.1. Pressure transducer setup for modern vehicles. ............................................................ 4

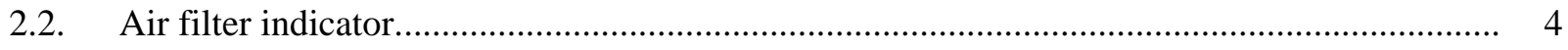

2.3. 2007 Buick Lucerne filter restriction .......................................................................... 7

2.4. 2007 Buick Lucerne filter restriction ................................................................................. 7

2.5. 1972 Pontiac Grandville air filter ................................................................................... 8

3.1. Maximum Outlet DP for 2007 Buick Lucerne baselined clean air filters ............................. 9

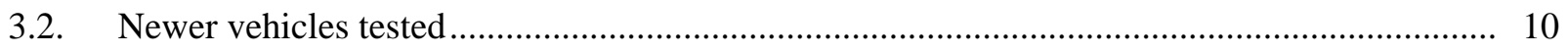

3.3. Average maximum Outlet DP for the 2003 Toyota Camry during

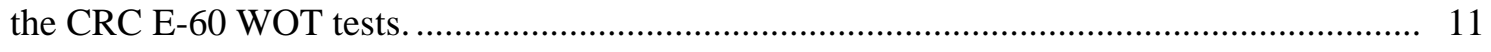

3.4. Average Outlet DP at 3000 RPM during the CRC E-60 WOT tests...................................... 11

3.5. Average maximum Outlet DP for SS WOT tests............................................................... 12

3.6. Air filter damage from WOT testing 2006 Dodge Charger ................................................ 13

3.7. Acceleration time for CRC E-60 WOT tests..................................................................... 13

3.8. Fuel economy for 2003 Toyota Camry ....................................................................... 14

3.9. Fuel economy for 2007 Buick Lucerne ...................................................................... 15

3.10. Fuel economy for 2006 Dodge Charger ....................................................................... 15

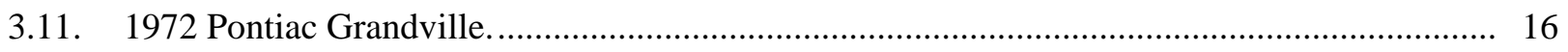

3.12. Pressure port location for 1972 Pontiac Grandville. ............................................................ 16

3.13. Outlet DP for 1972 Pontiac Grandville during CRC E-60 WOT............................................ 17

3.14. Outlet DP for 1972 Pontiac Grandville during SS WOT. ..................................................... 18

3.15. Acceleration time for 1972 Pontiac Grandville during WOT tests ........................................ 18

3.16. Fuel economy for 1972 Pontiac Grandville........................................................................ 19

3.17. Air filter average Outlet DPs for 1972 Pontiac Grandville during double HFET.................... 20

3.18. Damaged air filter from severely clogged air filter testing, 1972 Pontiac Grandville. ............. 20

3.19. FTP fuel economy for 1972 Pontiac Grandville............................................................... 21

3.20. HFET fuel economy for 1972 Pontiac Grandville. ............................................................ 21

3.21. Average double HFET lambda for 1972 Pontiac Grandville. .............................................. 22

3.22. Damaged air filter from severely clogged air filter testing, 2007 Buick Lucerne.................... 23

3.23. Air filter average double HFET Outlet DP for 2007 Buick Lucerne. ..................................... 24

3.24. Severely clogged air filter fuel economy for 2007 Buick Lucerne. ....................................... 24 



\section{ACRONYMS AND DEFINITIONS}

$\begin{array}{ll}\text { AFR } & \text { air : fuel ratio } \\ \text { CRC } & \text { Coordinating Research Council } \\ \text { DOE } & \text { U.S. Department of Energy } \\ \text { DP } & \text { pressure differential } \\ \text { ECE } & \text { Economic Commission for Europe (used in referring } \\ & \text { to driving cycles: ECE 15) } \\ \text { EPA } & \text { U.S. Environmental Protection Agency } \\ \text { FEERC } & \text { Fuels, Engines, and Emissions Research Center } \\ \text { FTP } & \text { ORNL) } \\ \text { HFET } & \text { Federal Test Procedure (EPA) } \\ \text { MDS } & \text { Highway Fuel Economy Test (EPA) } \\ \text { HC } & \text { Multi-Displacement System } \\ \text { lambda } & \text { hydrocarbon } \\ \text { kPa } & \text { excess air factor (AFR/stoichiometric AFR) } \\ \text { OEM } & \text { kilopascals (pressure unit) } \\ \text { ORNL } & \text { original equipment manufacturer } \\ \text { SI } & \text { Oak Ridge National Laboratory } \\ \text { SS } & \text { spark ignition } \\ \text { stoichiometric AFR } & \text { steady speed } \\ & \text { AFR at which complete combustion would produce } \\ \text { only carbon dioxide and water (no excess fuel or } \\ \text { excess air) } \\ \text { total hydrocarbons } \\ \text { WOT }\end{array}$





\section{ACKNOWLEDGEMENTS}

This report and the work described were sponsored by the U.S. Department of Energy (DOE) Office of Energy Efficiency and Renewable Energy Vehicle Technologies Program. The authors gratefully acknowledge the support of Dennis Smith and Kevin Stork at DOE. Several Oak Ridge National Laboratory staff made important contributions to this work, including Bob Boundy, Robert Gibson, Ron Graves, David Greene, Janet Hopson, Ron Lentz, Larry Moore, Scott Sluder, and John Thomas. The authors also wish to thank Donnie Baldwin at Honeywell, John Hoard at the University of Michigan, and Coleman Jones at General Motors for their thorough review and constructive recommendations. While these experts provided valuable guidance and information as noted above, this does not constitute endorsement by their organizations of either the study or the results. Grateful acknowledgement is also due to V. J. Ewing and Sandi Lyttle for their dedication in preparation of the final manuscript. 



\section{INTRODUCTION AND BACKGROUND}

The U.S. Department of Energy (DOE) Office of Energy Efficiency and Renewable Energy and the U.S. Environmental Protection Agency (EPA) jointly maintain a fuel economy website (www.fueleconomy.gov), which helps fulfill their responsibility under the Energy Policy Act of 1992 to provide accurate fuel economy information [in miles per gallon (mpg)] to consumers. The site provides information on EPA fuel economy ratings for passenger cars and light trucks from 1985 to the present and other relevant information related to energy use such as alternative fuels and driving and vehicle maintenance tips. In recent years, fluctuations in the price of crude oil and corresponding fluctuations in the price of gasoline and diesel fuels have renewed interest in vehicle fuel economy in the United States. (User sessions on the fuel economy website exceeded 20 million in 2008 compared to less than 5 million in 2004 and less than 1 million in 2001.) As a result of this renewed interest and the age of some of the references cited in the tips section of the website, DOE authorized the Oak Ridge National Laboratory (ORNL) Fuels, Engines, and Emissions Research Center (FEERC) to initiate studies to validate and improve these tips. This report documents a study aimed specifically at the effect of engine air filter condition on fuel economy.

A vehicle's published EPA fuel economy rating is determined by driving the vehicle over prescribed cycles on a chassis dynamometer. In the United States, city fuel economy is measured using the Urban Dynamometer Driving Schedule, also known as the Federal Test Procedure (FTP). Highway fuel economy is measured using the Highway Fuel Economy Test (HFET). Another relevant test is the US06, an aggressive (high speed, high load) test used to confirm emissions compliance during aggressive driving. Typically, fuel economy results from this test are not reported, but EPA uses them to adjust the FTP and HFET results, and these adjusted fuel economy rates are what are reported on the vehicle manufacturer's window sticker, in the Fuel Economy Guide, ${ }^{1}$ and on the fueleconomy.gov website.

Vehicle design, including mass, rolling resistance, aerodynamic drag, and engine and transmission efficiency, is an important factor affecting a vehicle's fuel economy on the prescribed driving schedules. Fuel economy can also be greatly affected by driver/owner behavior. Hard acceleration, excessive idling, and carrying unnecessary weight can all negatively affect fuel economy. Proper vehicle maintenance, on the other hand, can help the vehicle perform as it was designed, thus positively affecting fuel economy, emissions, and the overall drivability of a vehicle.

The study described in this report investigates the effect of one of these maintenance factors, air filter replacement, on vehicle performance and fuel economy. Past studies have indicated that replacing a clogged or dirty air filter can improve vehicle fuel economy. For example, Jaroszczyk, Wake, and Connor reported in 1993 that proper filtration systems make engines more fuel efficient; however, they gave no data or reference information to support this claim. ${ }^{2}$ The Organization for Economic Co-operation and Development claimed in a 1981 report based on earlier research by the Thornton Research Center that "excessive pressure across a dirty air filter" can cause a $1-15 \%$ increase in fuel consumption. ${ }^{3}$ In the Thornton study, six 1970-73 model year vehicles were tested using the Economic Commission for Europe hot-start driving cycle (ECE 15) to explore the fuel economy effects of "deliberate malfunctions," defined as maintenance problems such as damaged spark plugs, poor idle mixture, improper idle speed, and "restricted air cleaners." " Of the six vehicles, only five were tested with restricted air filters, accomplished by "masking the cross-sectional area of the air cleaner element." ${ }^{4}$ No further description of how the amount of restriction was quantified was given, but the vehicles showed a variable response to

the testing. Two of the vehicles showed less than a 1\% decrease in fuel economy, two others showed $11 \%$ and $15 \%$ decreases in fuel economy, and the fifth vehicle showed a decrease in fuel economy of more than $30 \%$ due to the restricted air cleaner. ${ }^{4}$ The Thornton researchers believed that this large change was due to the style of carburetor used in this 1971 Vauxhall Viva, which utilized a fixed-jet atmospherically 
vented carburetor, believed by the researchers to be very sensitive to a throttled air intake. ${ }^{4}$ The wide variability in the effect of restricted air intake from a simulated clogged air filter was attributed to the different styles of carburetors, which varied among the tested vehicles. ${ }^{4}$

The results of the Thornton Research Center tests are of limited use to consumers today because the vehicle engine technology has evolved significantly since those tests were conducted. As of the early 1980s, some form of closed-loop fuel control had been implemented on most U.S. light-duty vehicles to enable them to meet the EPA Tier 0 emissions standards. The authors hypothesized that the fuel economy of modern closed-loop feedback systems would not be sensitive to the state of the air filter, given that the engine power is controlled by throttling the intake air. Because of this, at a given engine power condition (or given manifold pressure) additional throttling from a clogged air filter would be offset by further opening the throttle (to achieve the same manifold pressure); however, maximum engine power would be expected to be affected by the intake air restriction imposed by a clogged filter. While the authors hypothesized that the fuel economy of modern engines would not be affected by a clogged filter, we further hypothesized that a clogged filter might impact a carbureted engine due to a "choking effect" in which the engine operates at richer combustion conditions.

This report describes a DOE-funded investigation into the effects of clogged air filters on the fuel economy of three modern vehicles, ranging from 2003 to 2007, that use closed-loop fuel control and a vintage 1972 vehicle equipped with a carburetor. The objectives of the program included

- determining the effects of clogged air filters on the fuel economy and performance of modern vehicles,

- confirming the results of previous studies indicating that clogged filters affect the fuel economy of carbureted or open-loop control vehicles, and

- determining other vehicle performance impacts of clogged filters (e.g., the potential impacts on engine power). 


\section{EXPERIMENTAL SETUP}

\section{$2.1 \quad$ TEST FACILITIES}

Testing was conducted at the ORNL FEERC. The FEERC chassis dynamometer is of the twin-roll type [21.625-inch (0.55-meter) diameter] with an eddy current brake. Conventional emissions measurements were conducted with analyzers from California Analytical Instruments. Nondispersive infrared sensors were used to measure carbon dioxide $\left(\mathrm{CO}_{2}\right)$ and carbon monoxide (CO), and heated chemiluminescence detectors were used to measure nitrogen oxides $\left(\mathrm{NO}_{\mathrm{x}}\right)$. Total hydrocarbons (THC) and methane were measured with a heated flame ionization detector with a methane cutter. Fuel economy was calculated from the integrated "bag" emissions from the constant-volume dilution tunnel according to EPA and Code of Federal Regulations guidelines. In this method, total carbon in the exhaust from the measured $\mathrm{CO}_{2}$, CO, and THC emissions is used to compute fuel economy. The fuel used in all vehicles for all tests was Federal Certification Gasoline with known carbon fraction and density for computing fuel economy. Reported fuel economies are raw or unadjusted results, not directly comparable to window sticker or Fuel Economy Guide ${ }^{1}$ values.

\subsection{TEST SETUP}

The vehicles tested included the following.

- 2007 Buick Lucerne-3.8L V6.

- 2003 Toyota Camry-2.4L I4.

- 2006 Dodge Charger-5.7L V8 with MDS (Multi-Displacement System).

- 1972 Pontiac Grandville—455ci V8 with factory four barrel carburetor.

For each of the three modern vehicles, three different pressure differentials (DPs) were measured on the engine along with lambda excess air factor [nondimensional air : fuel ratio (AFR)] and tunnel emissions.

The DPs measured were as follows (see also Fig. 2.1).

- Inlet DP-The pressure differential between the area just before the air filter and the atmosphere.

- Filter DP - The pressure differential between the area just before the air filter and the area just after the air filter.

- Outlet DP-The pressure differential between the area just after the air filter and the atmosphere.

These pressures were measured using three separate electronic delta P pressure transducers. Each transducer was able to measure 0 to $7.5 \mathrm{kPa}$ ( 0 to 30 inches of water column). The sensors were calibrated before testing began using a water manometer. In a few experiments, the measured pressures exceeded the range of these sensors. This issue did not present itself as a significant problem until late in testing when "severe" test cases were explored (Sect. 3).

The Outlet DP measured was used to quantify the amount of restriction that was being added to the intake system by the "clogged filter." This pressure is the same pressure that is monitored by factory original equipment manufacturer (OEM) air filter indicators such as the one shown in Fig. 2.2. These filter indicators are used in some applications to alert the owner/operator when the air filter is in need of replacement. In most cases the Filter DP measurement and the Outlet DP measurement were nominally the same. Only the Outlet DP will be reported here as this is the value that a factory-installed indicator would measure. 


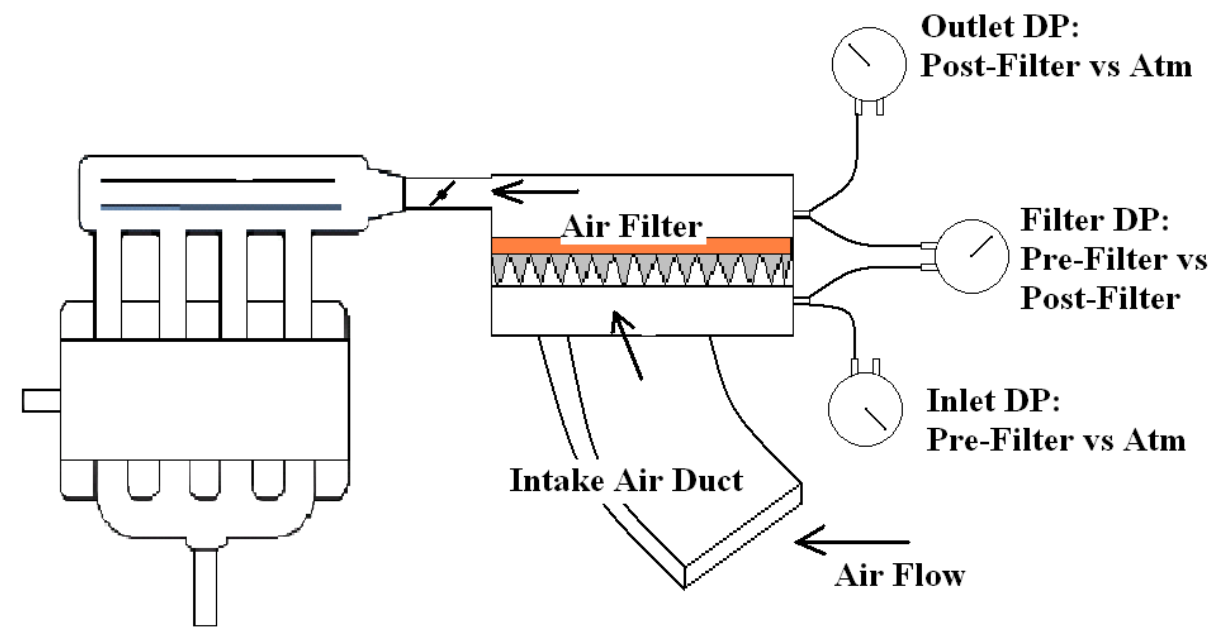

Fig. 2.1. Pressure transducer setup for modern vehicles.

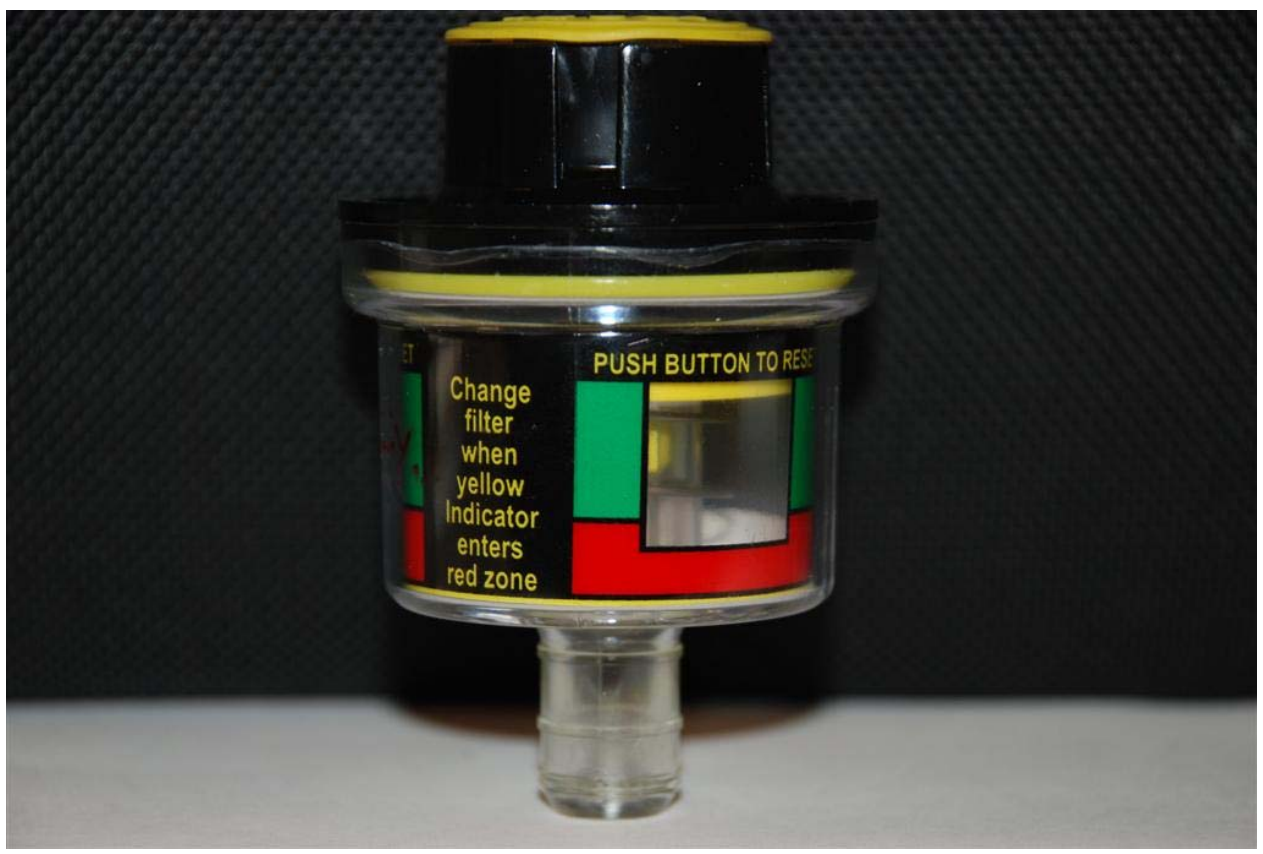

Fig. 2.2. Air filter indicator.

A factory OEM indicator was taken from a 2001 Chevrolet Silverado with 5.3L V8 and tested to find the Outlet DP required to "set" the indicator or move the yellow indicator into the red zone (see Fig. 2.2). Using a vacuum pump and water manometer to test the indicator, the authors determined that an Outlet DP of about $5.7 \mathrm{kPa}$ was needed to set the indicator to the level corresponding to a clogged air filter.

Other air filter indicators from diesel applications were also tested. Both of the other two air filter indicators tested were factory equipment for Dodge Ram pickup trucks with 5.9L diesel engines. One was purchased new from the Chrysler dealer and the other was taken from a 2006 Dodge Ram pickup equipped with a 5.9L diesel engine. Using the same vacuum pump and water manometer, the authors 
found that the vacuum needed to set these indicators was slightly less than that required by the indicator taken from the gasoline application. These air filter indicators only required about $4.2 \mathrm{kPa}$ to move the indicator to the level corresponding to a clogged air filter. Tests of diesel vehicles are planned as a followon effort to the work reported here.

\subsection{DEFINING A CLOGGED AIR FILTER}

The results of the testing of these air filter indicators agreed with the information found in the literature as to what the definition of a clogged air filter is in engineering terms. The function and design of intake air filters must address the following. ${ }^{5}$

1. Engine durability

2. Filtration

3. Flow management

4. Pressure or head loss constraints

5. Overall noise, vibration, and harshness standards

6. Service requirements

7. Packaging

8. Styling/appearance

9. Emissions

All of these functions are to be met for the service life of the filter without allowing engine performance to be affected. ${ }^{5}$ In light- and medium-duty applications, the service life is normally defined by accumulated mileage. However, it is very common for over-servicing to occur in these applications due to a lack of understanding of how optimum air filter efficiency is achieved. ${ }^{5,6}$ The standard recommended service life for an air filter in light- and medium-duty applications, during normal driving conditions, is about 30,000 miles. ${ }^{5-7}$ It is common, however, for servicing to occur when the filter appears dirty. Engine air filters are designed to actually increase their efficiency by using this initial layer of dust as an added filter layer. Initial filter efficiency is usually approximately $98 \%$ but increases to more than $99 \%$ by the end of the service life of the filter. ${ }^{7,8}$ Therefore, changing an air filter before the useful service life is achieved can result in premature engine wear. ${ }^{6,9}$

In engineering terms, the service life of an air filter is commonly defined as a level of restriction which results in a pressure drop across the filter of approximately $2.5 \mathrm{kPa}$ (10 in. water) more than the pressure drop of the new or clean filter. ${ }^{5,9-11}$ Bugli and Green define this as the "final pressure drop" when conducting tests to investigate filter cleaning procedures:

$$
\text { Final pressure drop }=\text { initial clean pressure drop }+2.5 \mathrm{kPa} .{ }^{10}
$$

According to Patil, Halbe, and Vora, it is common for air filter service indicators to be set between about 5.0 and $7.0 \mathrm{kPa}$, which corresponds to the setting of the unit taken from the Chevrolet Silverado. The unit tested from the 2006 Dodge Ram is set at a slightly lower level, which is believed to be due to the vehicle being equipped with a diesel engine. While the level of restriction on a closed-loop, feedback, throttled, spark-ignition (SI) engine would not be expected to affect fuel economy (as described above), the additional pumping loss might be expected to affect the fuel economy of the unthrottled diesel engine.

This restriction level is noted as the point of critical pressure drop because at levels greater than the "final pressure drop," overall engine performance begins to degrade significantly. $5,7,8,11$ 


\subsection{VEHICLE TESTING}

Wide-open throttle (WOT) tests were used to measure the changes in the filter pressure drop (Outlet DP). In a real-world application, the vacuum needed to set one of the air filter indicators would likely occur under heavy acceleration, such as merging onto an interstate, or climbing a steep grade. Therefore the level of restriction was set, using an artificial clogging technique described below, to achieve the desired Outlet DP during a WOT acceleration from idle to approximately $85 \mathrm{mph}$ or a steady-speed (SS) WOT test in which the dynamometer was held at a fixed speed, $65 \mathrm{mph}$, and the throttle was held open for 10 seconds. Using these test procedures, the 2007 Buick Lucerne was configured to achieve an Outlet DP of approximately $7.0 \mathrm{kPa}$ under the WOT acceleration and approximately $5.7 \mathrm{kPa}$ under the SS WOT. Once the method for achieving this restriction was developed, it was used with each vehicle. Using this approach, the V8-equipped Dodge Charger showed a slightly higher Outlet DP than the V6 Lucerne, and the I4 Camry showed a slightly lower Outlet DP. The 1972 V8 Pontiac was restricted in a similar manner and level. It is important to note that all the modern vehicles used rectangular cartridge style air filters (Figs. 2.3 and 2.4), while the 1972 Pontiac used the cylindrical filter element common in that era (Fig. 2.5).

For all of the vehicles, a warm-up test was run before starting the WOT cycles. The warm-up cycle consisted of 5 minutes at $50 \mathrm{mph}$ followed by 3 minutes at $30 \mathrm{mph}$. This 8 -minute warm-up was always conducted on a warm engine (i.e., the engine had been run earlier that day). The acceleration WOT tests were run first, followed by the SS WOT tests. Five of each WOT test were conducted. The acceleration WOT tests used a procedure known as the modified Coordinating Research Council (CRC) E-60 protocol. $^{12}$ The SS WOT tests were run by slowly accelerating the vehicle to approximately $65 \mathrm{mph}$, where the dynamometer control was set to hold a fixed speed. Once the vehicle speed reached $65 \mathrm{mph}$, the operator held this cruise condition for 10 seconds then opened the throttle to the WOT position for another 10 seconds. The vehicle was then brought back to idle for 30 seconds, and the process was repeated.

In all cases, the "new" air filter was a newly purchased aftermarket filter for that specific application. The simulated clogged air filter was another identical filter that was blocked off with a series of disposable shop towels to create the desired pressure drop. For the newer vehicles, the shop towels were placed in the air box on the upstream side of the air filter to increase the resistance of the air flowing through, as shown in Figs. 2.3 and 2.4. In the case of the 1972 Pontiac, the round filter was wrapped with shop towels to create the desired resistance, as shown in Fig. 2.5. Before the procedure for simulating a clogged filter was established, several filters were tested on the 2007 Buick. The OEM air filter was found to have a slightly higher pressure drop at WOT than several aftermarket air filters. The aftermarket filters were used for this testing to generate the largest difference between "clean" and "clogged" for these experiments.

Other methods of restriction were considered before we decided upon the use of shop towels. The idea of using an orifice plate was decided against due to the fear of not having a consistent restriction across a range of flow rates or engine speeds. Loading the filter with particles such as soil or flour was not considered to be repeatable or feasible due to the handling issues that would result. Taping off sections of the filter could be used to accomplish the desired pressure drop; however, this approach would not result in uniform restriction across the full area of the filter. In addition, completely blocking off sections of the filter could affect the flow dynamics of the inlet system. Paint was also considered but rejected due to drying time, the inability to reduce pressure drop if set too high, and the potential for undesirable HC emissions. Thus the use of shop towels was adopted to generate a repeatable air filter pressure drop.

After establishing the WOT test procedure for quantifying the filter state, the standard EPA test cycles, FTP, HFET, and US06 (see Sect. 1.1), were run in triplicate to test for fuel economy or emissions effects. 
Fuel economy values reported for the HFET and US06 are from the second of the two cycles. For both cycles, common practice is to conduct the cycle twice, reporting only the data from the second cycle.

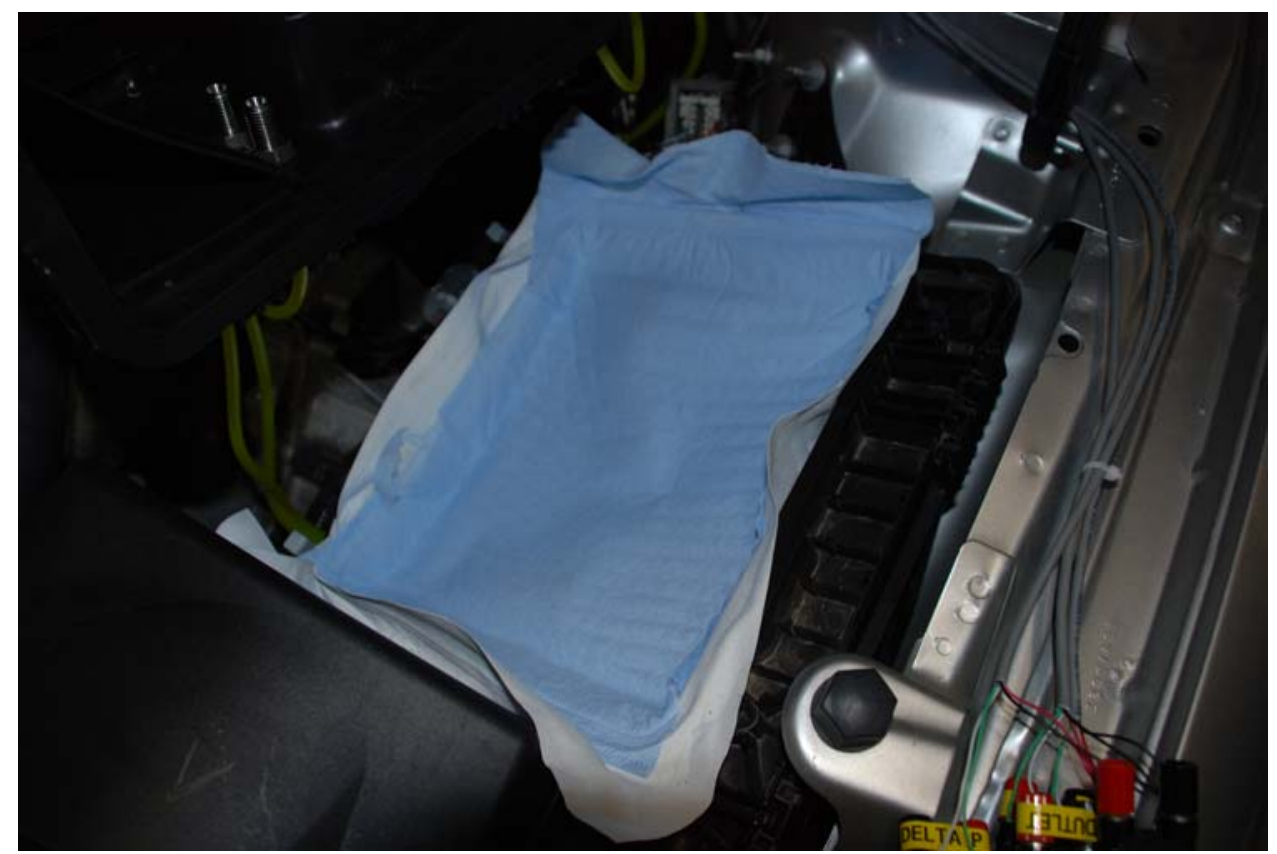

Fig. 2.3. 2007 Buick Lucerne filter restriction. Shop towels inserted into air box upstream of the air filter.

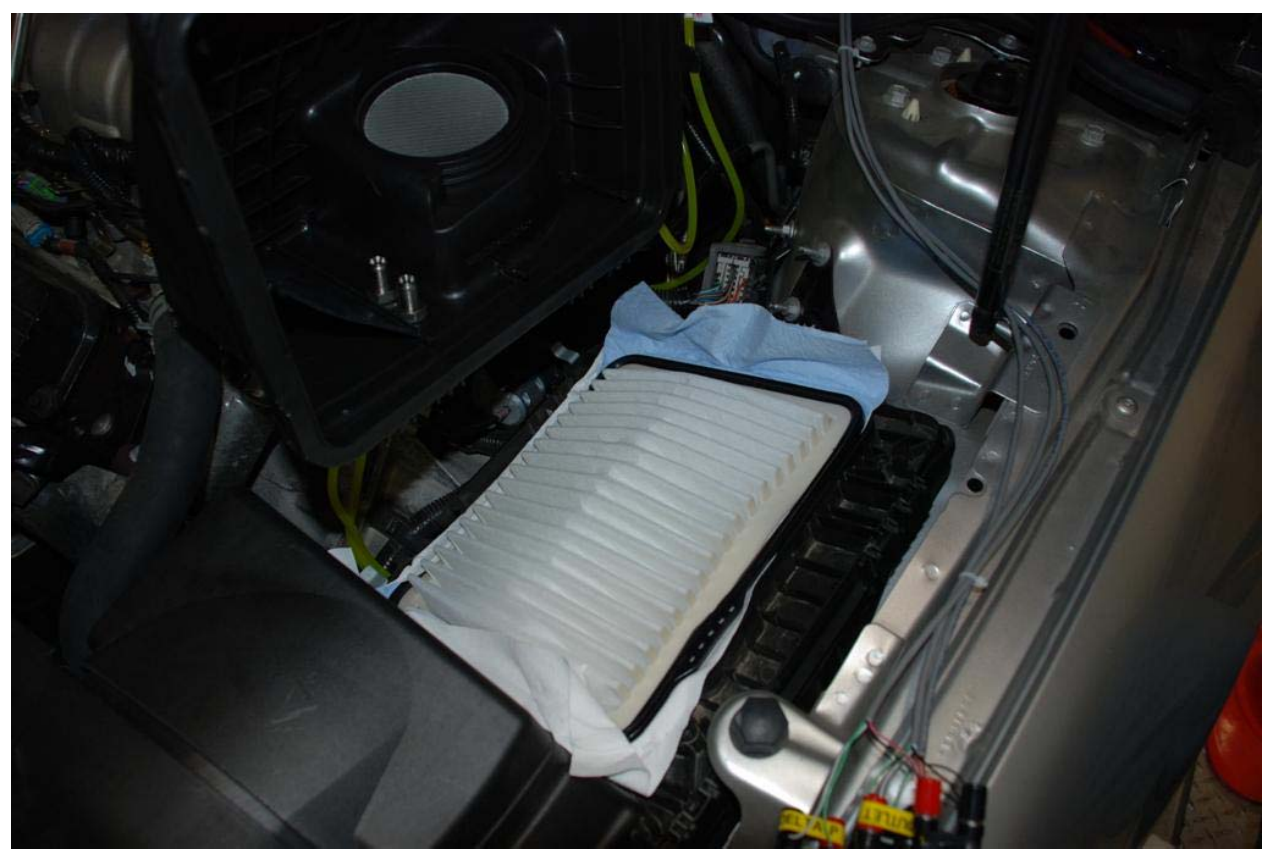

Fig. 2.4. 2007 Buick Lucerne filter restriction. Shop towels inserted into air box upstream of the air filter. 


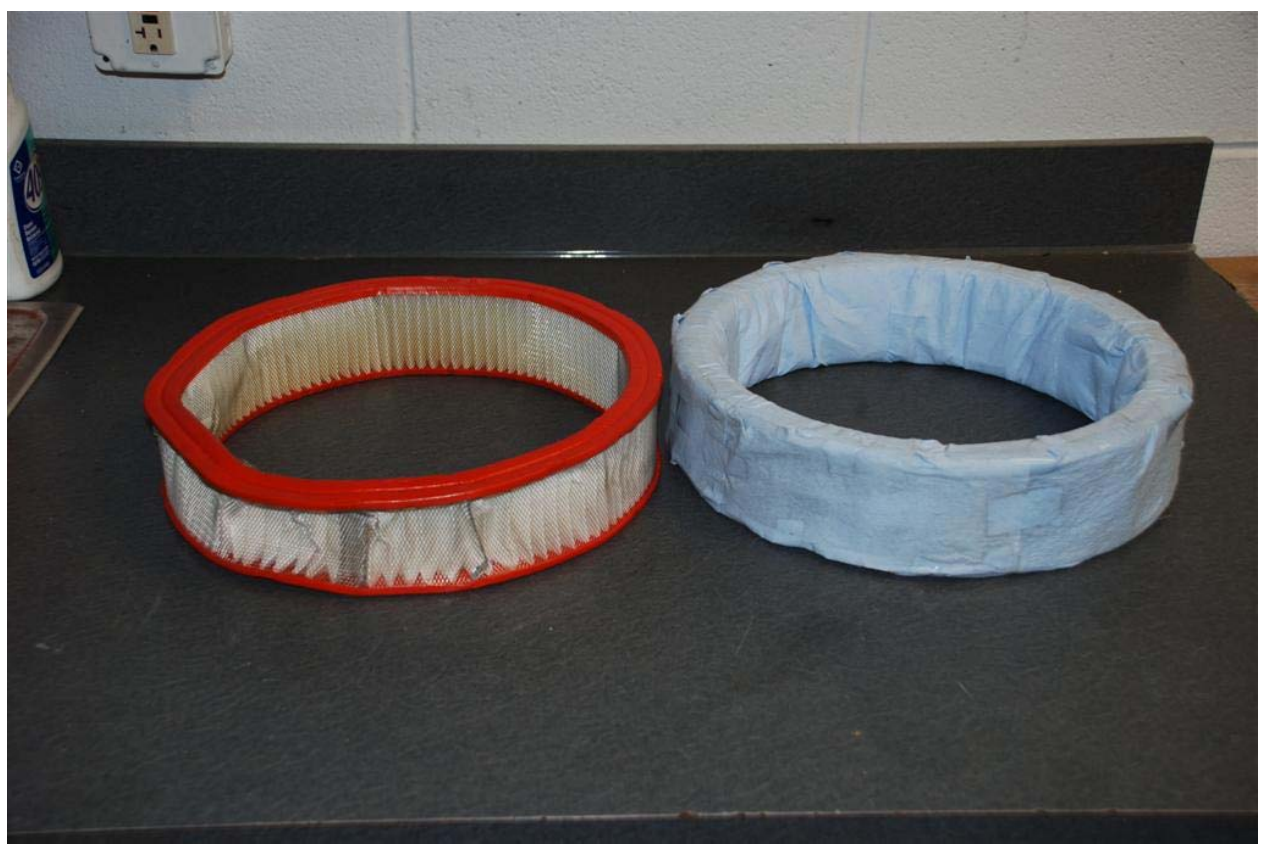

Fig. 2.5. 1972 Pontiac Grandville air filter. Filter on the left shows damage that occurred during "severely clogged” filter testing (see Sect. 3.3.1). 


\section{RESULTS AND DISCUSSION}

\subsection{MODERN VEHICLES}

\subsubsection{Initial Testing}

Four filter setups, an OEM filter, an aftermarket filter, a performance aftermarket filter, and no filter, were tested, using the 2007 Buick Lucerne as the test vehicle, to determine a baseline and the filter to be used for the remainder of the testing. Each setup was tested over the WOT cycle described previously. It was observed that the OEM filter resulted in a higher Outlet DP than the aftermarket filter and the performance aftermarket filter, as is shown in Fig. 3.1. The aftermarket filter was chosen for the test process due to its lower initial Outlet DP compared to the OEM filter and because it is more common than the performance aftermarket filter; thus, it allowed us to explore the largest clean-to-clogged difference for a commonly used air filter. No measureable differences were observed in vehicle performance with these filters over the CRC E-60 WOT test cycle.

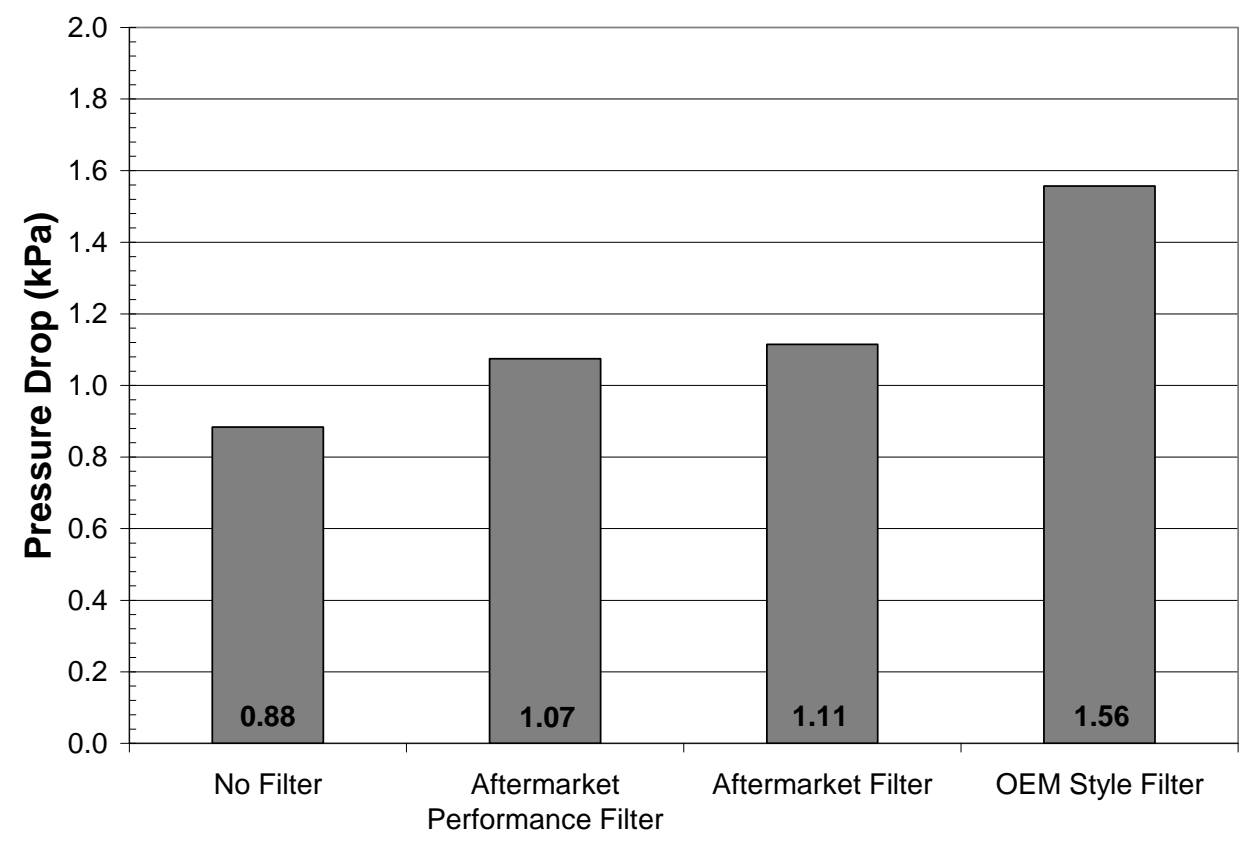

Fig. 3.1. Maximum Outlet DP for 2007 Buick Lucerne baselined clean air filters. Initial testing done to baseline multiple clean air filters.

\subsubsection{WOT Testing}

Each of the three newer vehicles listed in Sect. 2.2 was tested in the same manner to compare the effects of a clean versus a clogged filter. The vehicles are shown in Fig. 3.2. Each vehicle was instrumented with the electronic delta P pressure transducers reading Inlet DP, Filter DP, and Outlet DP during testing. The restriction level was initially set using the 2007 Buick Lucerne, equipped with a 3.8L V6, such that the maximum Outlet DP was about 7.0-7.2 kPa during the CRC E-60 WOT tests and about 5.7-6.0 kPa during the SS WOT tests. Both conditions would allow for a common air filter indicator to be set, indicating to the user that the vehicle's air filter should be changed. Once the restriction level was determined, the same number and style of disposable shop towels were used for each vehicle to simulate a similar degree of clogging. This approach resulted in a slight variance of the Outlet DP depending on the 
vehicle due to differences in filter area and engine displacement. In all cases the restriction was on the order of 6.0-7.0 kPa, adequate to set a common air filter indicator.

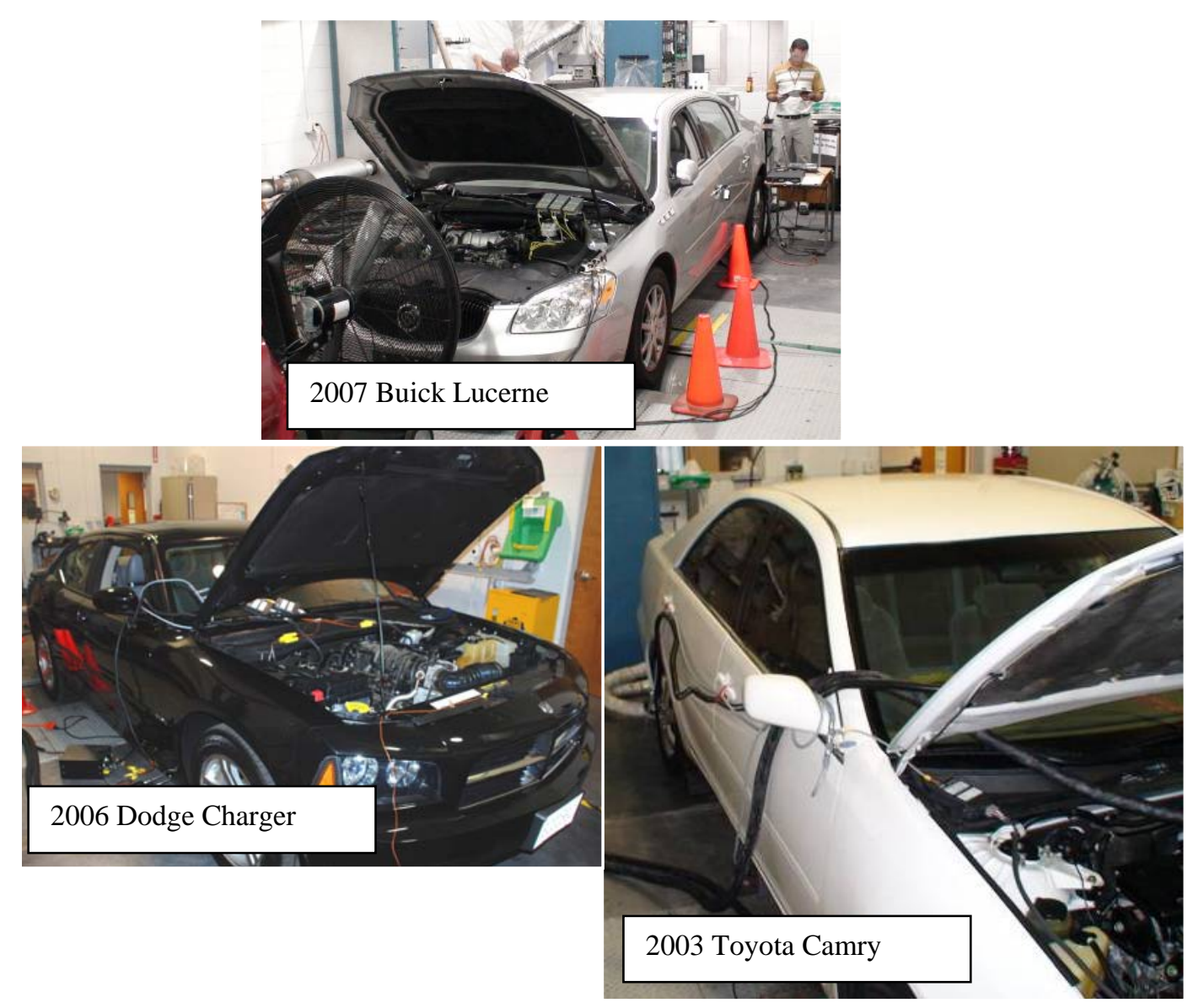

Fig. 3.2. Newer vehicles tested.

For the 2003 Camry, which was equipped with a 2.4L I4, the clogged filter created an Outlet DP in excess of $6.2 \mathrm{kPa}$ for the CRC E-60 WOT tests (Fig. 3.3), while the new filter produced less than $1.7 \mathrm{kPa}$ under the same acceleration conditions. For the SS WOT tests (Fig. 3.4), the clogged filter created an Outlet DP in excess of $4.2 \mathrm{kPa}$, while the new filter generated approximately $0.5 \mathrm{kPa}$ under the same acceleration conditions. The data in Fig. 3.3 represent the Camry’s average maximum Outlet DP recorded for the WOT accelerations during the CRC E-60 WOT section of the test.

For the 2006 Dodge Charger, which was equipped with a 5.7L V8 with MDS, the clogged filter resulted in an increase of the Outlet DP compared to the Lucerne. The Charger testing resulted in a maximum Outlet DP in excess of $7.5 \mathrm{kPa}$ for the CRC E-60 WOT tests and approximately 7.2-7.5 kPa for the SS WOT tests. The MDS is Chrysler's cylinder deactivation system. This system disables the intake and exhaust valves and fuel delivery for four cylinders during low-load operation to reduce pumping losses and improve part-load fuel economy. This system was monitored during testing by collecting fuel injector pulse width data from two injectors, one which is intermittently deactivated by the MDS and one which is not. 


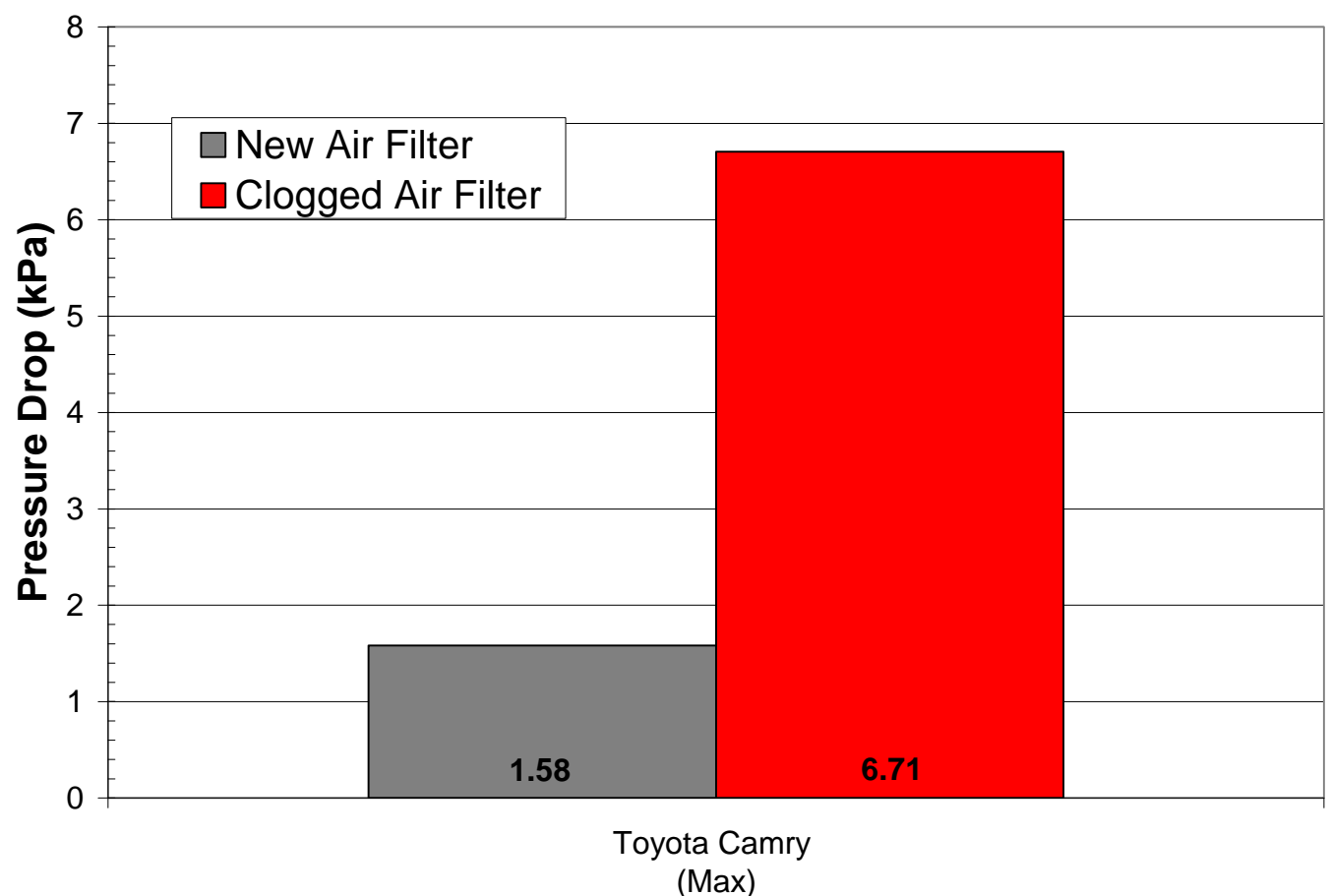

Fig. 3.3. Average maximum Outlet DP for the 2003 Toyota Camry during the CRC E-60 WOT tests.

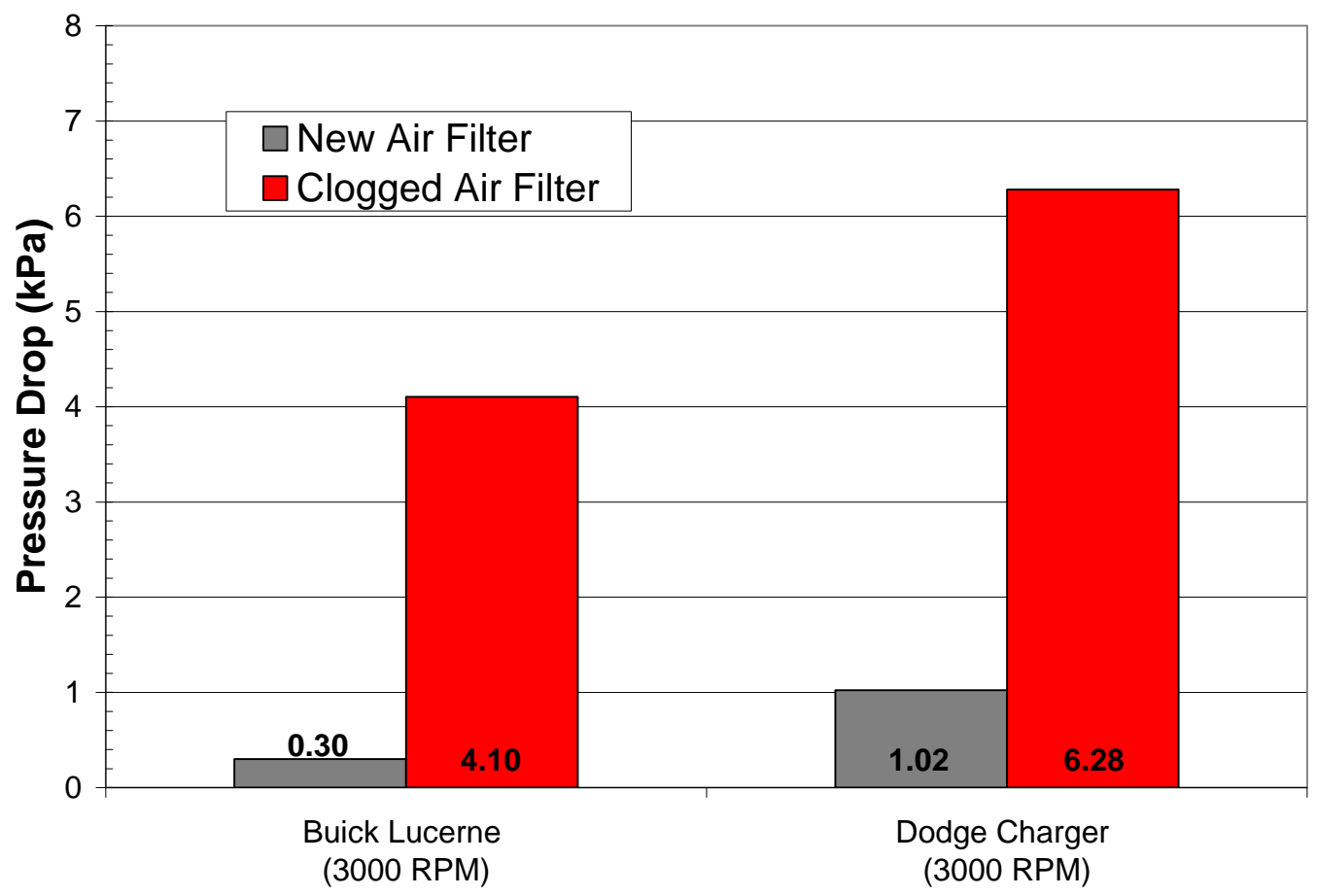

Fig. 3.4. Average Outlet DP at 3000 RPM during the CRC E-60 WOT tests.

Because the peak Outlet DP for the Charger and Lucerne were outside the range of the sensor in the clogged state, the average of the Outlet DPs at 3000 RPM, recorded for each of the WOT accelerations 
during the CRC E-60 WOT section of the test, was used to compare these vehicles, as shown in Fig. 3.4. The Outlet DP values for the SS WOT tests were all within the range of the sensor and are shown in Fig. 3.5.

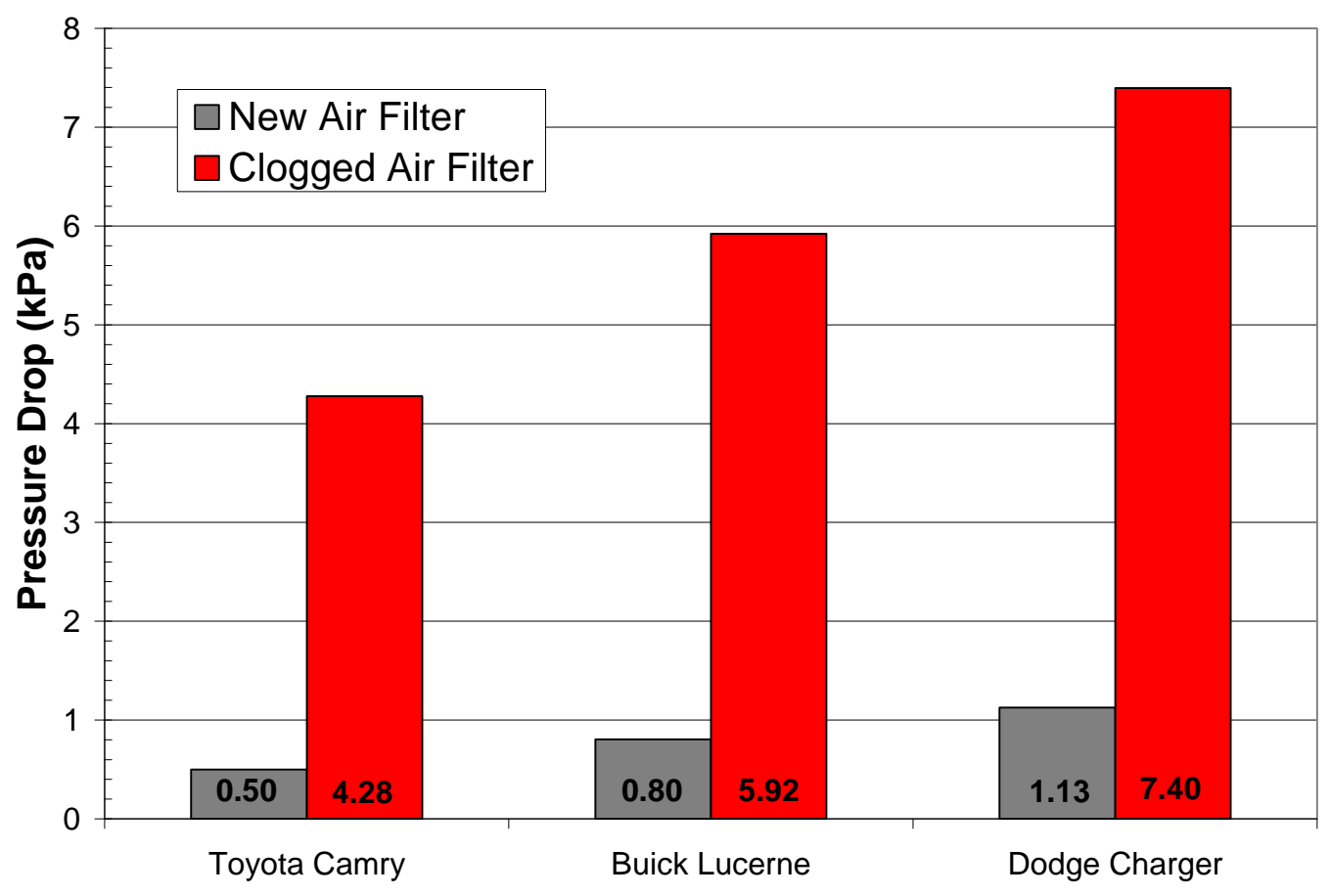

Fig. 3.5. Average maximum Outlet DP for SS WOT tests.

For the Lucerne, the Outlet DP at 3000 RPM during the initial acceleration of the CRC E-60 WOT tests was in excess of $4 \mathrm{kPa}$ for the clogged filter and less than $0.4 \mathrm{kPa}$ for the new filter (Fig. 3.4). During the SS WOT tests the clogged filter created an Outlet DP in excess of $5.7 \mathrm{kPa}$, while the new filter Outlet DP was less than $0.9 \mathrm{kPa}$ (Fig. 3.5).

For the Charger, the Outlet DP at 3000 RPM during the initial acceleration of the CRC E-60 WOT tests was in excess of $6.2 \mathrm{kPa}$ for the clogged filter, while that for the new filter was less than $1.1 \mathrm{kPa}$ under the same acceleration conditions (Fig. 3.4). During the SS WOT tests the clogged filter created an Outlet DP in excess of $7.2 \mathrm{kPa}$, while the new filter Outlet DP was less than $1.2 \mathrm{kPa}$ under the same acceleration conditions (Fig. 3.5).

Also, for the Charger, under these acceleration conditions with the filter clogged, the pressure drop was so severe that the air filter was actually dislodged from its position in the air cleaner box and pulled into the intake hose. Fig. 3.6 shows the damage that was done to the air filter as a result of these clogged air filter WOT tests.

Figure 3.7 shows the acceleration times for the vehicles with both a clogged and new air filter. The data were analyzed from 20 to $80 \mathrm{mph}$ to ensure that the vehicle was at WOT, removing any driver induced variability. The WOT protocol requires the vehicle to be accelerated at WOT from idle to $85 \mathrm{mph}$. The driver reported being able to "feel" the restriction created by the clogged filter and sense the decreased acceleration for both the Camry and Lucerne. The Charger was 0.6 seconds slower in the clogged state, but the driver reported no noticeable decrease in acceleration. 


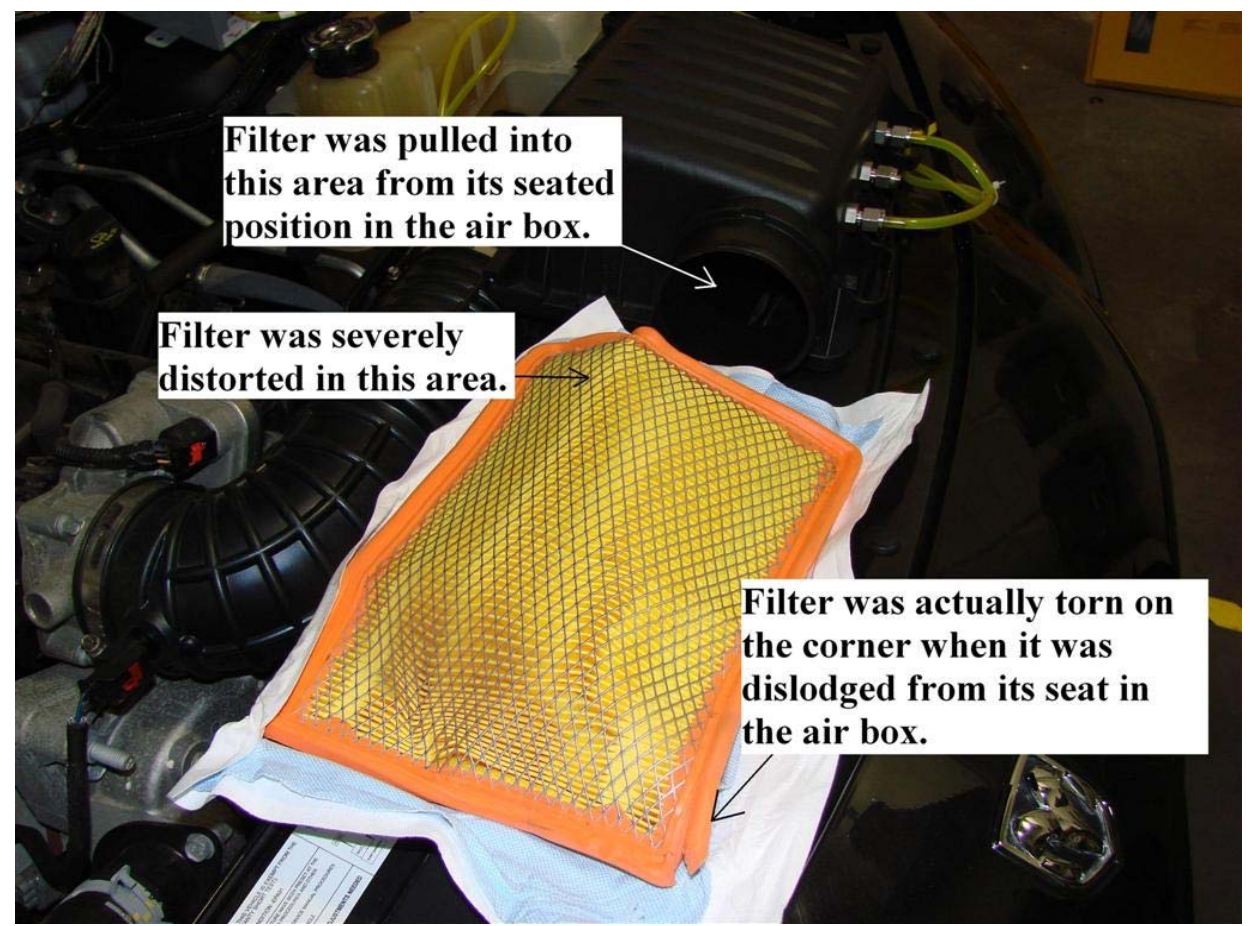

Fig. 3.6. Air filter damage from WOT testing 2006 Dodge Charger. Filter was damaged due to the pressure drop across the filter, resulting in the filter being torn out of its seat in the air box.

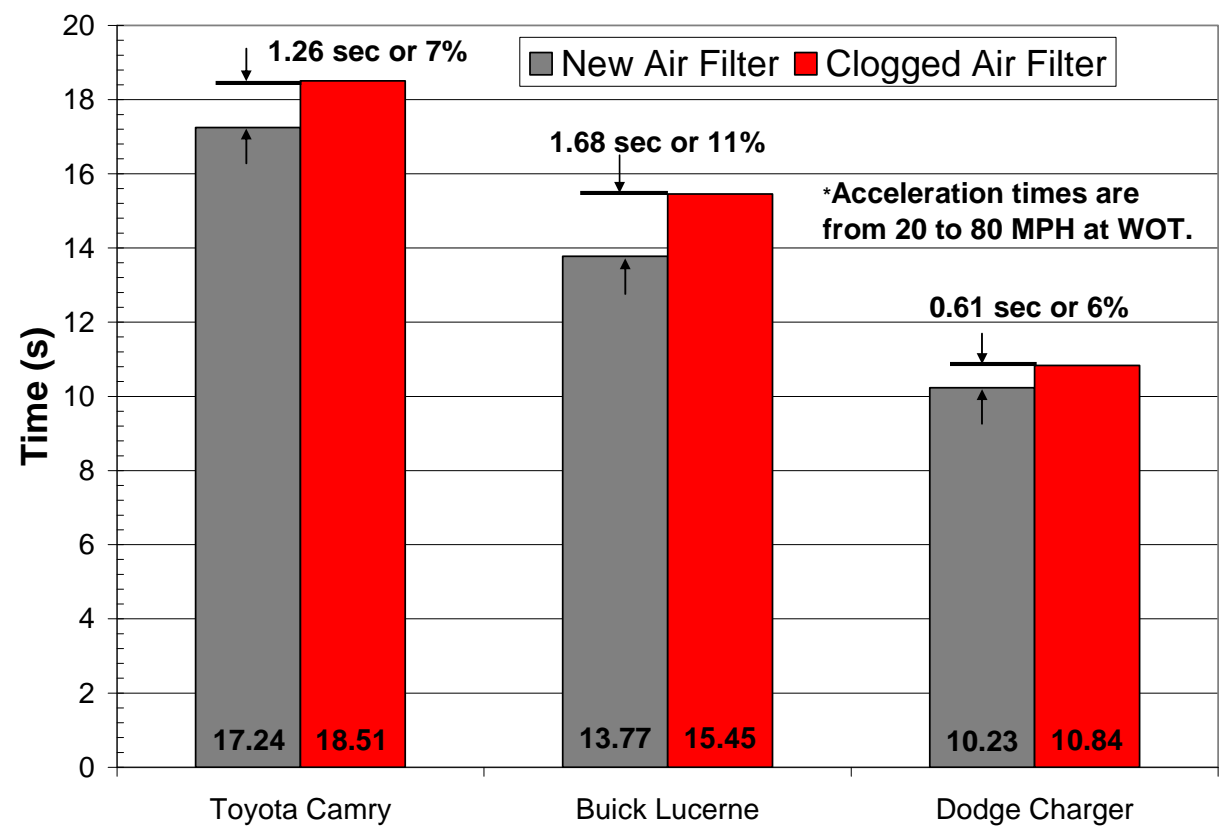

Fig. 3.7. Acceleration time for CRC E-60 WOT tests. Data are averaged from the five accelerations of the CRC E-60 cycle. 


\subsubsection{Performance and Fuel Economy}

The simulated clogged filter significantly affected vehicle performance, increasing the time to accelerate from 20 to $80 \mathrm{mph}$ by 0.6 to 1.7 seconds on the three vehicles. The Outlet DP measured for each vehicle was sufficient for setting a common air filter indicator to the "change" or "clogged" position. For each vehicle, the Outlet DP at some point exceeded $5 \mathrm{kPa}$ and showed an increase over the clean filter in excess of $2.5 \mathrm{kPa}$, a common standard for defining a dirty air filter. ${ }^{5,9-11}$

Despite the filter restrictions, however, no significant changes in fuel economy were observed. Each vehicle was run through at least three rounds of FTP, HFET, and US06 tests with the new air filter, and the same protocol was repeated with the clogged air filter. The tests were conducted on consecutive days for each vehicle. This format was used to allow for the required soak time to perform a cold FTP each morning. The resulting fuel economy data for the vehicles are shown in Figs. 3.8, 3.9, and 3.10. Range bars in the figures show the minimum and maximum of the tests for each case, while the columns show the average. Test-to-test repeatability is within about 1.5\%, and all of the variances between the new and clogged air filter cases are similarly within about $1.7 \%$. The baseline fuel economies for the vehicles were all within $0-6 \%$ of unadjusted EPA certification database values (www.epa.gov) for similar vehicles.

The changes observed by clogging the air filter produced no significant effect on the fuel economy of the vehicles tested, when tested over these three standard cycles that represent a wide range of driving conditions. It is possible that there may be some isolated operating conditions under which the fuel economy may be more susceptible to a clogged air filter. However, such operating conditions are not likely to be consistent from vehicle to vehicle. The three driving cycles used here are representative of a wide range of driving conditions, as described in Sect. 1.

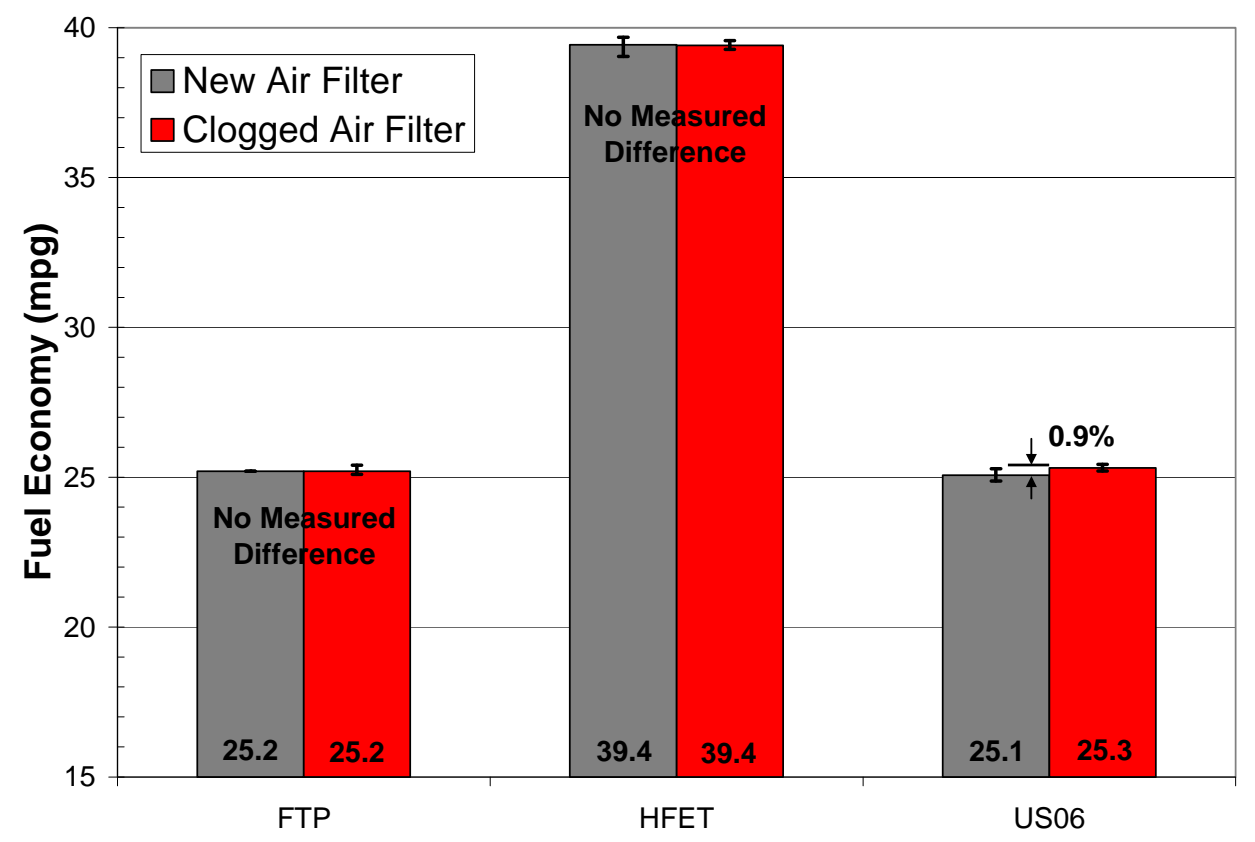

Fig. 3.8. Fuel economy for 2003 Toyota Camry. Data are averaged over the three tests conducted for each cycle and configuration. Range bars show the minimum and maximum for each data set. 


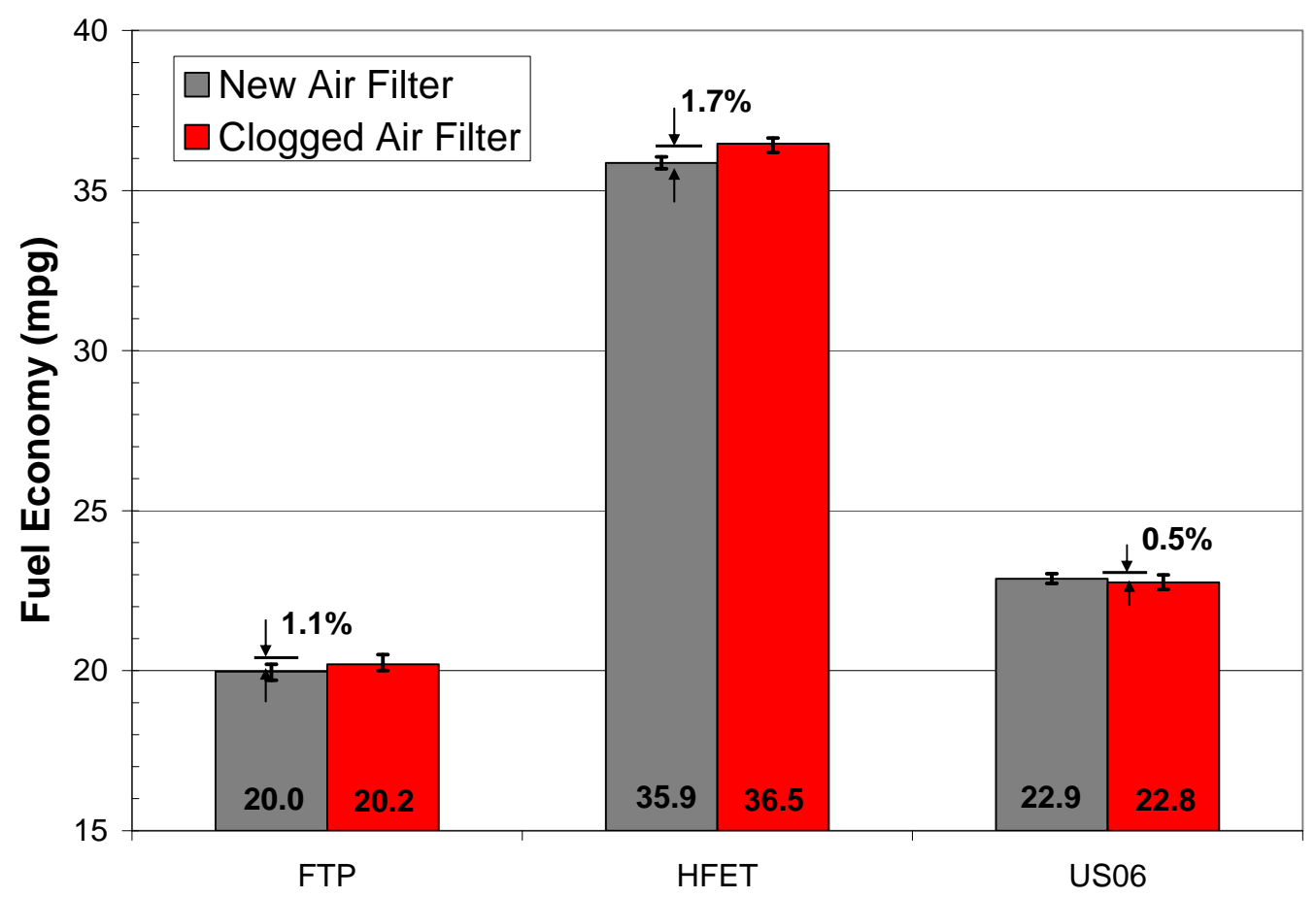

Fig. 3.9. Fuel economy for 2007 Buick Lucerne. Data are averaged over the four tests conducted for each cycle and configuration. Range bars show the minimum and maximum for each data set.

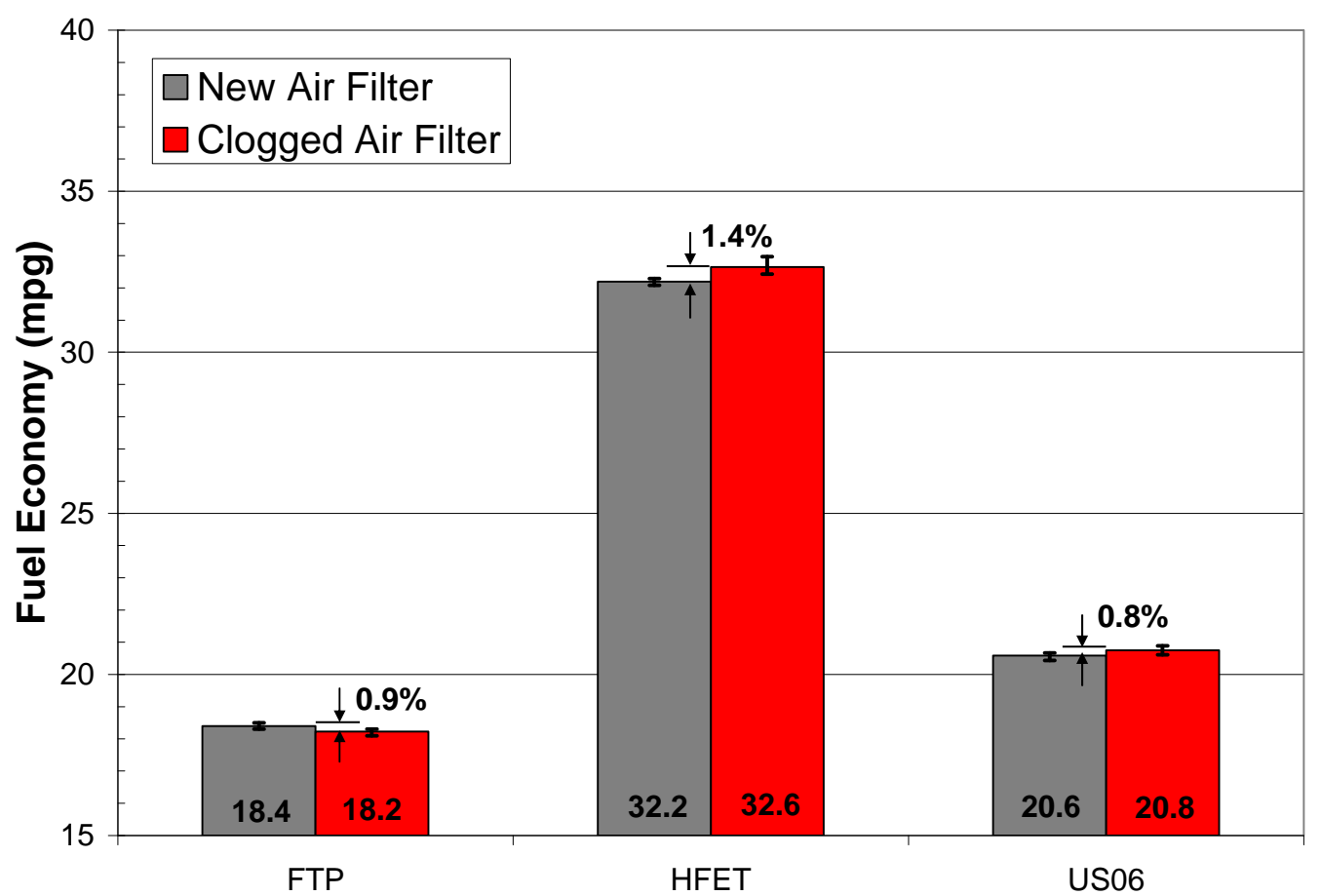

Fig. 3.10. Fuel economy for 2006 Dodge Charger. Data are averaged over the three tests conducted for each cycle and configuration. Range bars show the minimum and maximum for each data set. 


\subsection{CARBURETED VEHICLE-1972 PONTIAC GRANDVILLE}

To investigate the effect of a clogged air filter on a carbureted engine, a 1972 Pontiac Grandville with a 455ci V8 engine was also tested (Fig. 3.11). The Pontiac was only instrumented with the electronic delta P pressure transducer reading the Outlet DP during testing, configured so that it measured the pressure after the air filter and referenced that to the ambient air pressure. This setup is shown in Fig. 3.12.

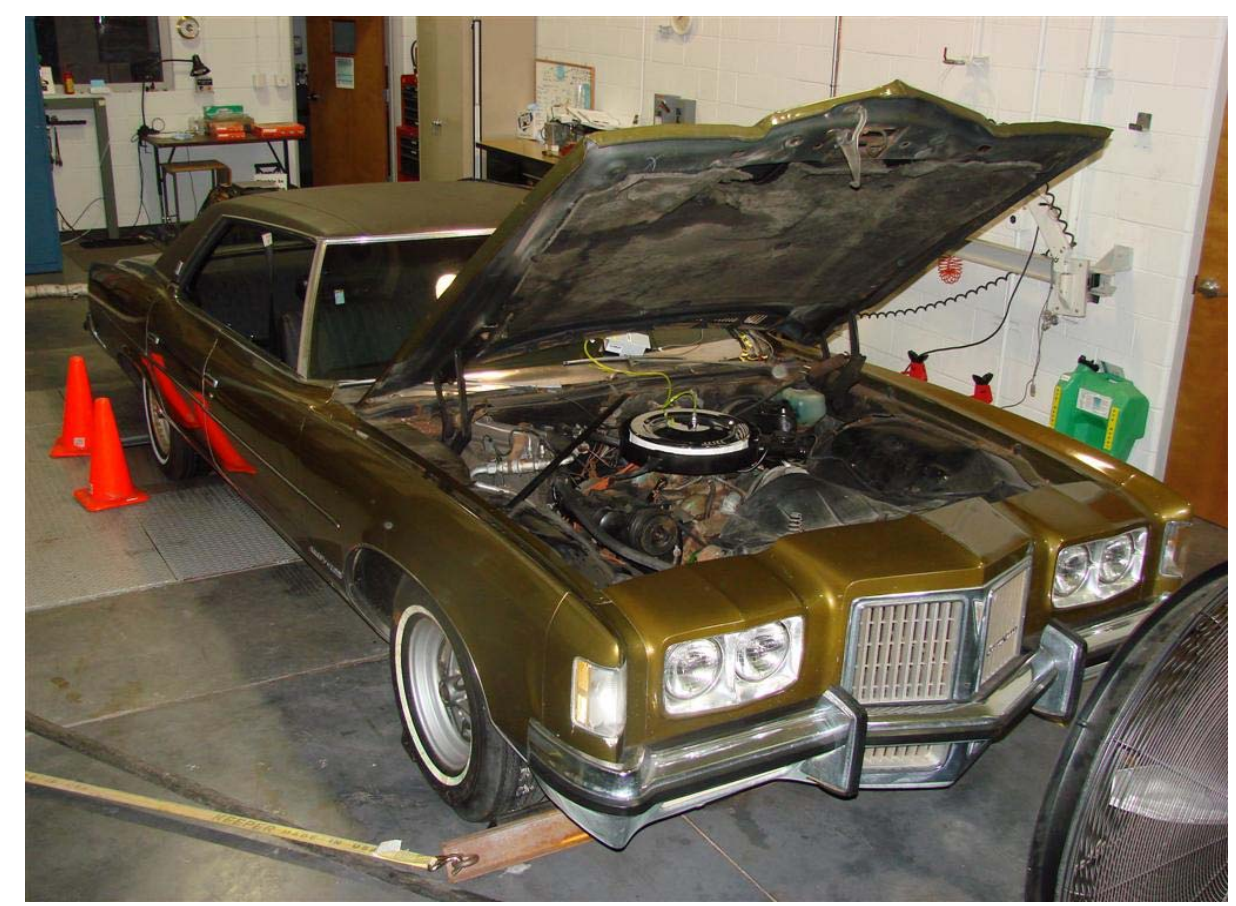

Fig. 3.11. 1972 Pontiac Grandville.

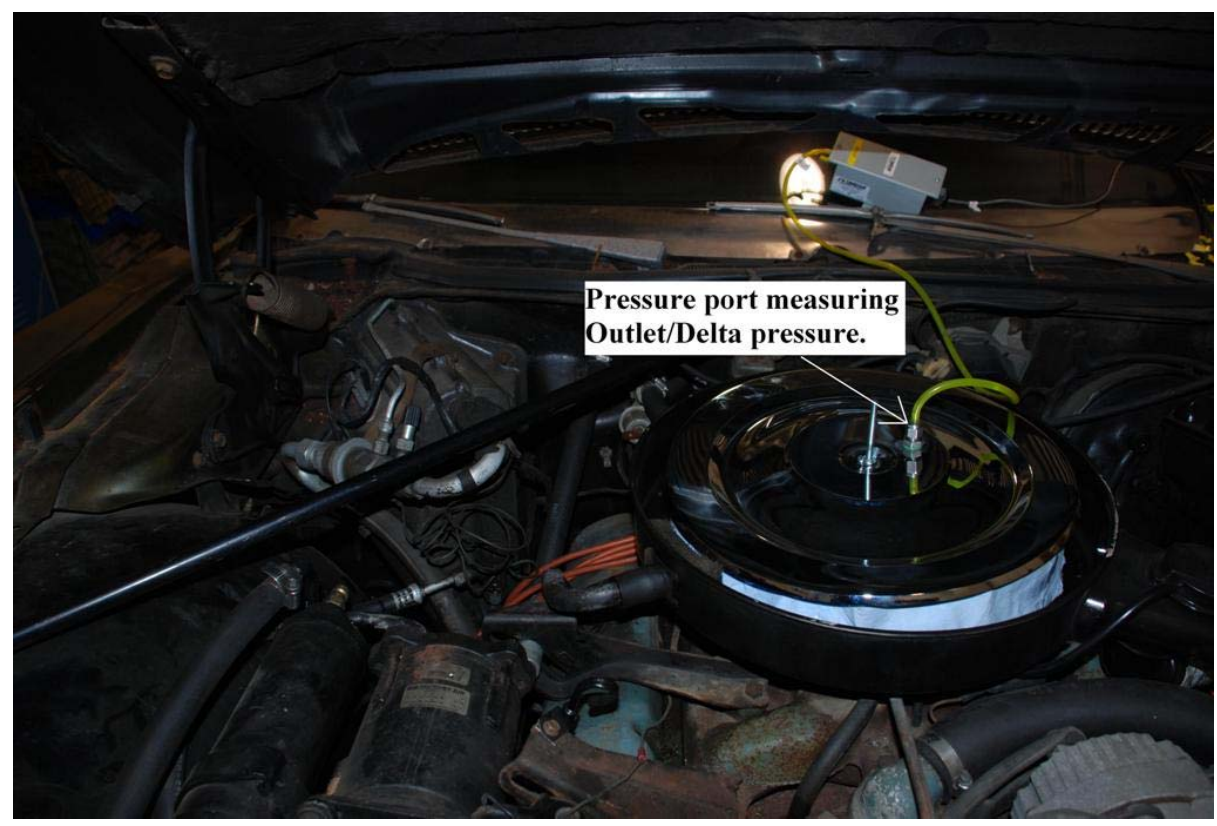

Fig. 3.12. Pressure port location for 1972 Pontiac Grandville. 
The restriction level was set in the same manner as for the other vehicles. The shop towels were cut and taped to the outside of the round air filter used by the Pontiac. This setup was used to correlate with the restriction that was applied to the other vehicles. The WOT cycles were both decreased from five accelerations to three accelerations each to minimize wear and tear on this vintage vehicle. During the CRC E-60 WOT accelerations and during the SS WOT tests, the maximum Outlet DP exceeded the range of the sensor. Both conditions would allow for a common air filter indicator to be set, indicating to the user that the vehicle's air filter should be changed.

Also, under these acceleration conditions with the filter clogged, the pressure drop was so severe that the air filter was crushed slightly in one area.

The Outlet DPs for the new filter and simulated clogged filter from the CRC E-60 WOT and SS WOT tests are shown in Figs. 3.13 and 3.14. The peak Outlet DP for the clogged filter is in excess of $7.5 \mathrm{kPa}$ for the CRC E-60 WOT-the sensor is at its maximum range for each of the accelerations-while that for the new filter is less than $0.75 \mathrm{kPa}$ under the same acceleration conditions. For the SS WOT tests, the clogged filter again showed an Outlet DP in excess of $7.5 \mathrm{kPa}$, while the new filter again showed less than $0.75 \mathrm{kPa}$ under the same acceleration conditions. These results can be considered analogous to the Filter DP because the sensor was reading the post-filter pressure versus the ambient pressure. This means that, in both WOT cases, the clogged filter was exhibiting a pressure drop greater than $7.5 \mathrm{kPa}$ across the air filter. Because of time constraints, we proceeded with testing rather than waiting to procure a sensor with a larger range.

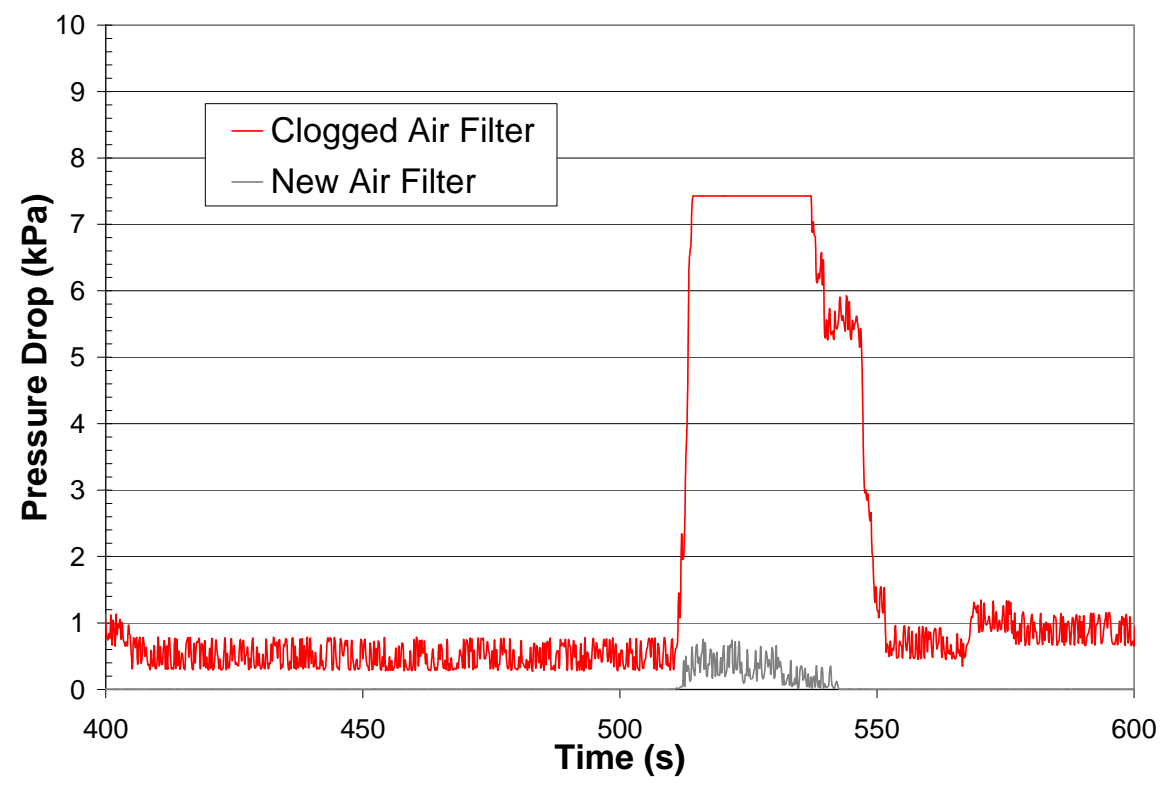

Fig. 3.13. Outlet DP for 1972 Pontiac Grandville during CRC E-60 WOT. 


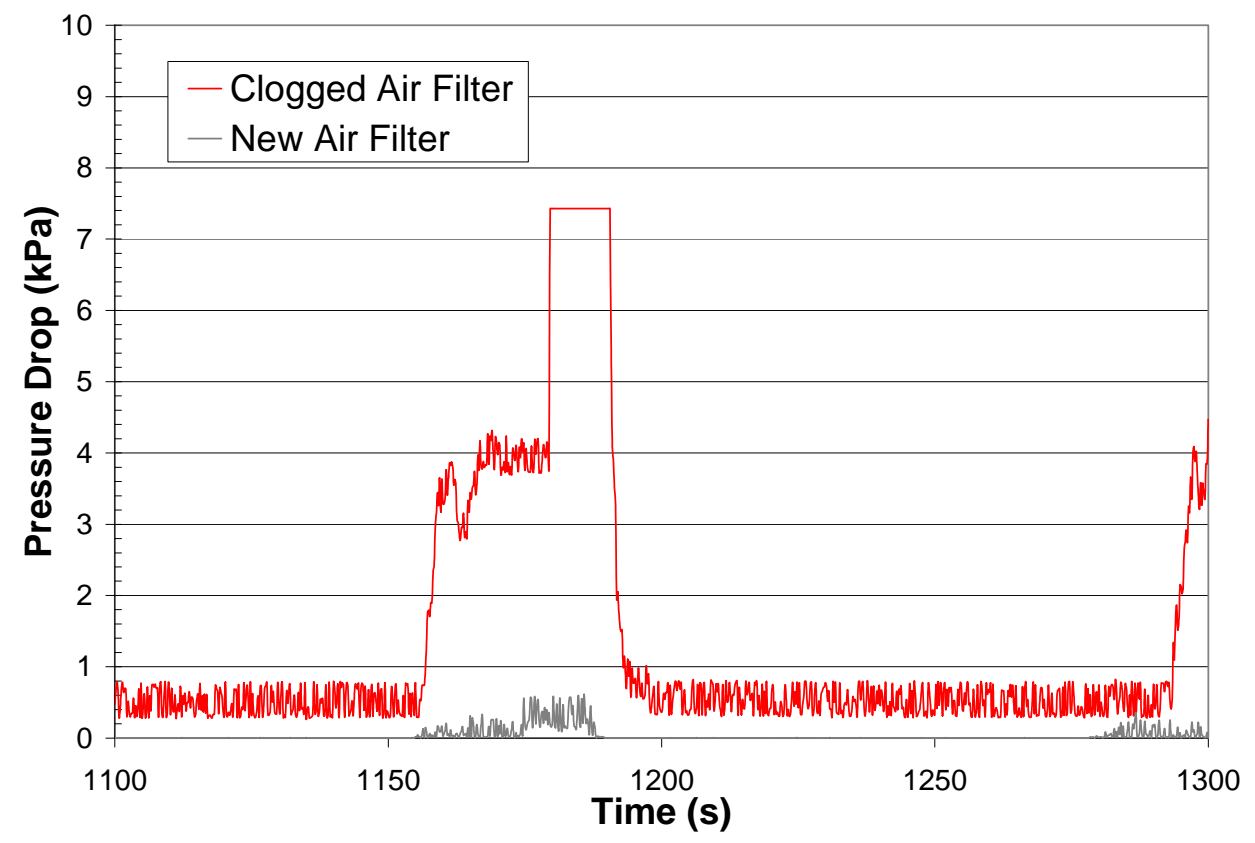

Fig. 3.14. Outlet DP for 1972 Pontiac Grandville during SS WOT.

Figure 3.15 shows that in the clogged filter scenario, the average time it took to accelerate from 20 to 80 mph during the WOT tests increased by about 3.73 seconds or $23 \%$. The driver reported a noticeable loss of performance during the WOT testing with the simulated clogged filter.

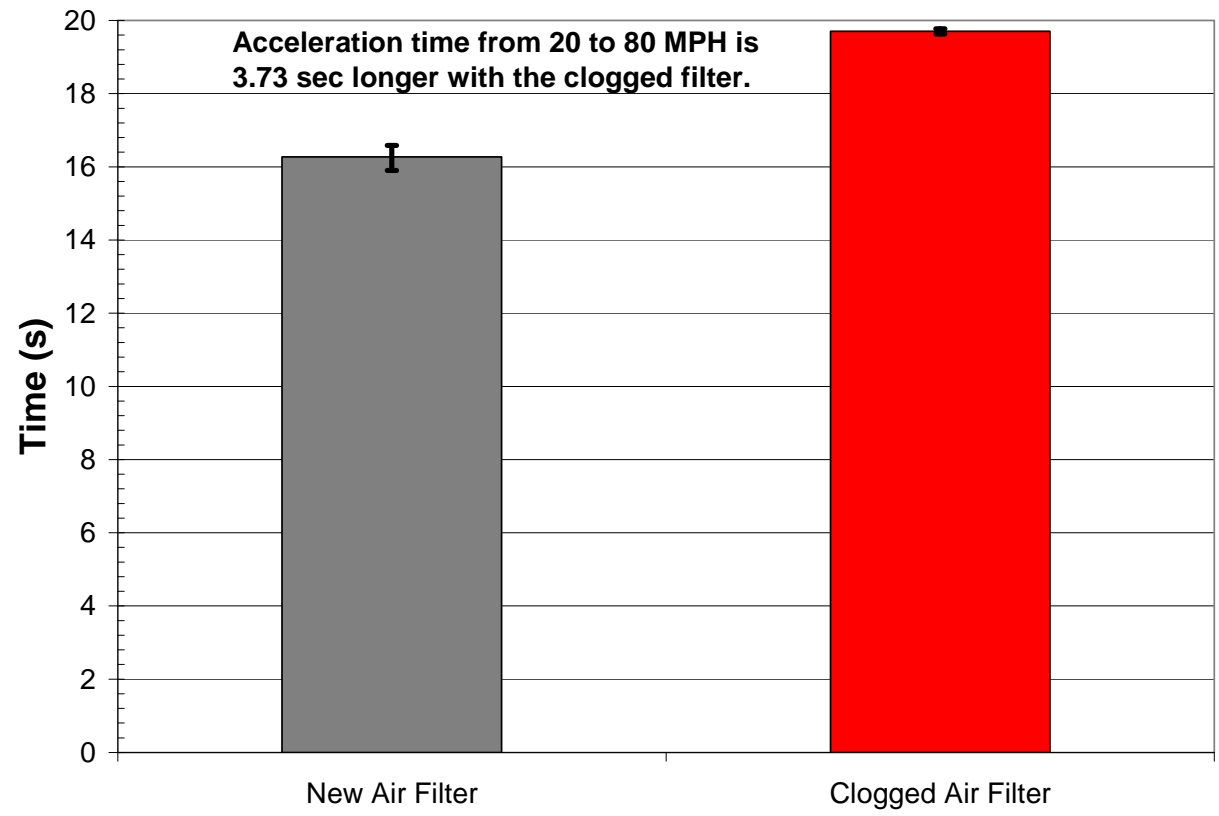

Fig. 3.15. Acceleration time for 1972 Pontiac Grandville during WOT tests. Data are averaged over the three CRC-E60 accelerations from 20 to $80 \mathrm{mph}$ with the throttle at $100 \%$. Range bars show the minimum and maximum for each data set.

The Pontiac was run through three rounds of FTP and HFET tests with the new air filter, and the same protocol was repeated with the clogged air filter. The US06 tests were not conducted after two failed 
attempts to complete that cycle with this vehicle. The US06 cycle requires aggressive accelerations and has extended periods of high speed operation (up to $80 \mathrm{mph}$ ). The 1972 Pontiac overheated during these high speed sections of the US06. Therefore, to avoid damaging the vehicle, the US06 tests were not conducted. The FTP and HFET tests were conducted on consecutive days, with each test being run once per day, similar to the other vehicles. This format was used to allow for the required soak time to perform a cold FTP each morning. The resulting fuel economy data for the Pontiac are shown in Fig. 3.16. Test-totest repeatability is within about $1.8 \%$ for the Pontiac, and the new versus clogged cases show a drop of about $2 \%-2.5 \%$. The level of filter clog tested appears to have a small effect on the fuel economy of this carbureted vehicle although it is not as dramatic as some of the fuel economy differences reported in the literature. ${ }^{3}$

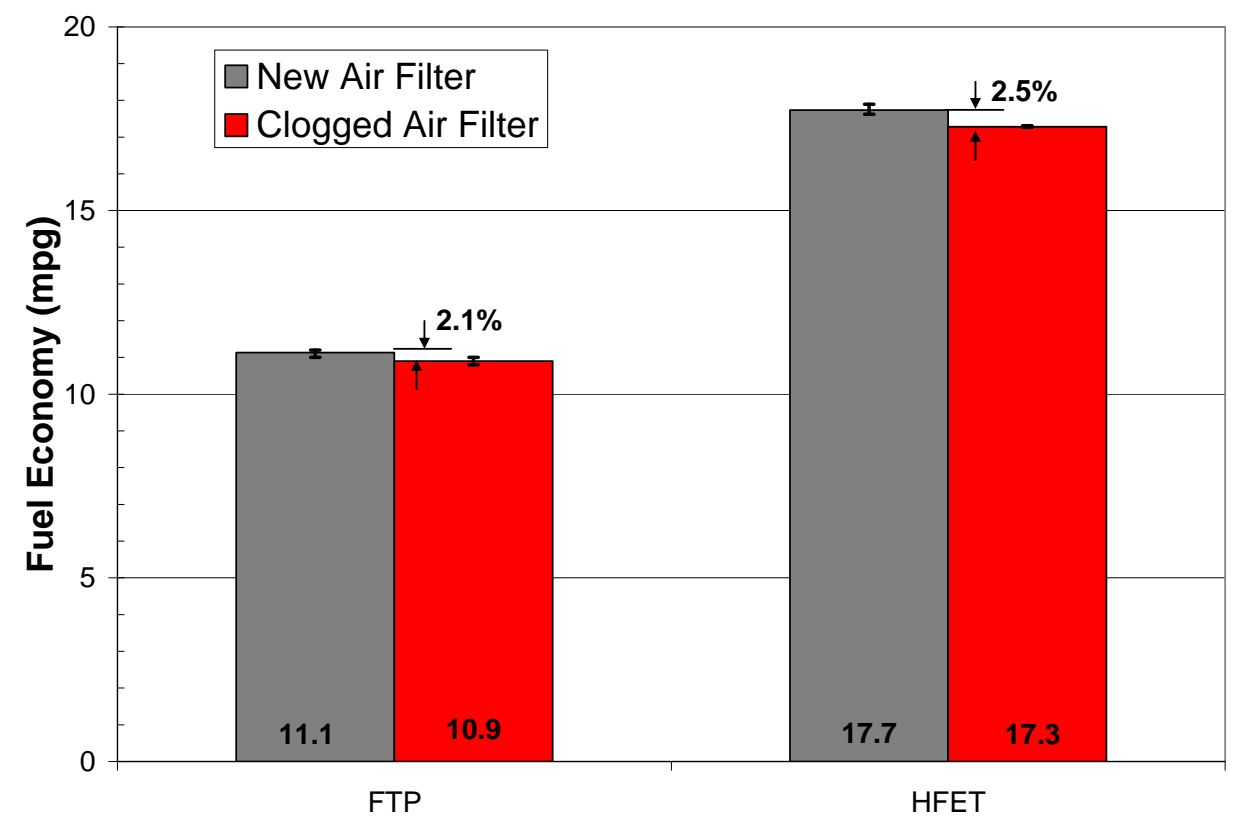

Fig. 3.16. Fuel economy for 1972 Pontiac Grandville. Data are averaged over the three tests conducted for each cycle and configuration. Range bars show the minimum and maximum for each data set.

\subsection{FURTHER INVESTIGATIONS-SIMULATING A SEVERELY CLOGGED FILTER}

\subsection{1 $\quad$ 1972 Pontiac Grandville}

While the filter restriction tested was severe enough to exceed $7.5 \mathrm{kPa}$ at WOT, it is conceivable that some consumers never experience WOT and could allow their filters to become even more severely clogged. In the interest of validating the large fuel economy penalties noted in the literature, further testing was conducted to investigate more severely clogged cases. The level of restriction was increased in stages to allow quantification of the maximum tolerable restriction that would still allow the vehicle to meet the HFET cycle. These increases were tested and quantified using the normal double HFET test procedure. The level of restriction was increased in three stages or tests until the vehicle was barely able to meet the required speed for the test. The average Outlet DPs measured over the double HFET for these three severely clogged filter tests are shown in Fig. 3.17 with the Outlet DPs for the originally tested clogged filter and new air filter. 


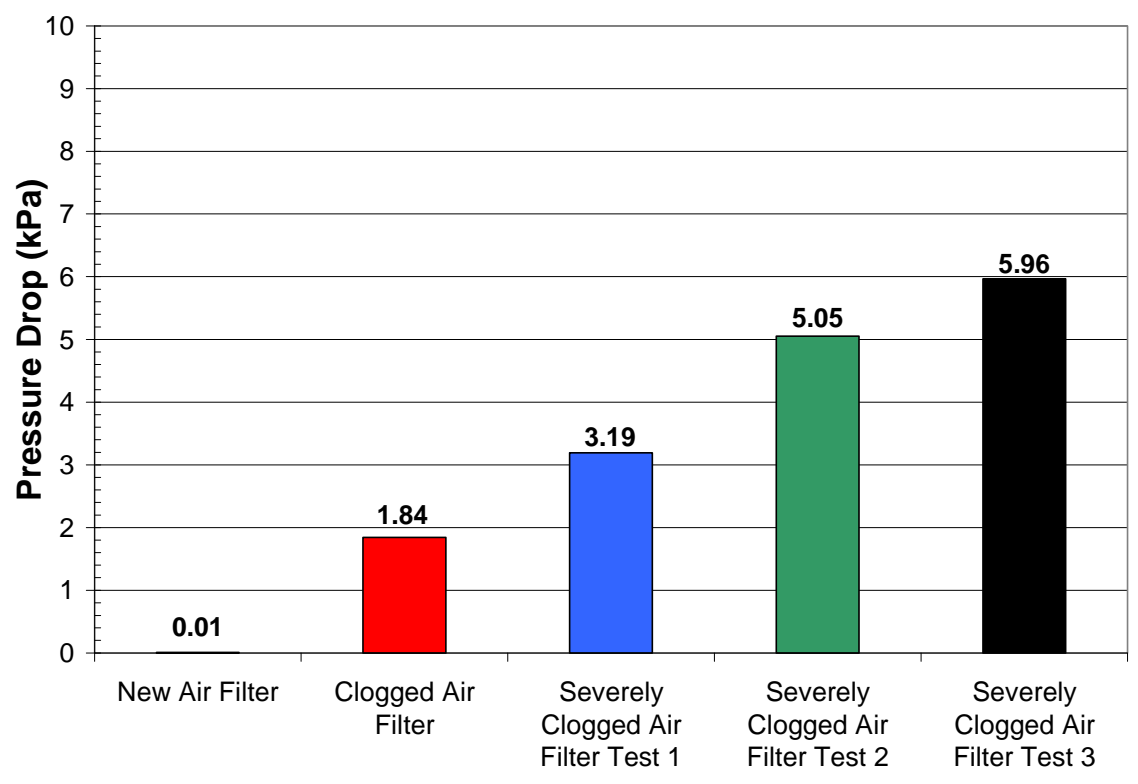

Fig. 3.17. Air filter average Outlet DPs for 1972 Pontiac Grandville during double HFET.

The filter restriction in the Severely Clogged Air Filter Test 3 configuration (black column, Fig.3.17) was so severe that the driver had to consciously drive the vehicle in a manner that would not increase the throttle fast enough to cause a rich misfire condition during the HFET cycle. Once rich misfire was encountered, the vehicle was not able to maintain speed, and therefore, the test was invalid. The Filter Test 3 configuration also resulted in the air filter being crushed by the air filter cover. Figure 3.18 shows a picture of the air filter after removal of the shop towels.

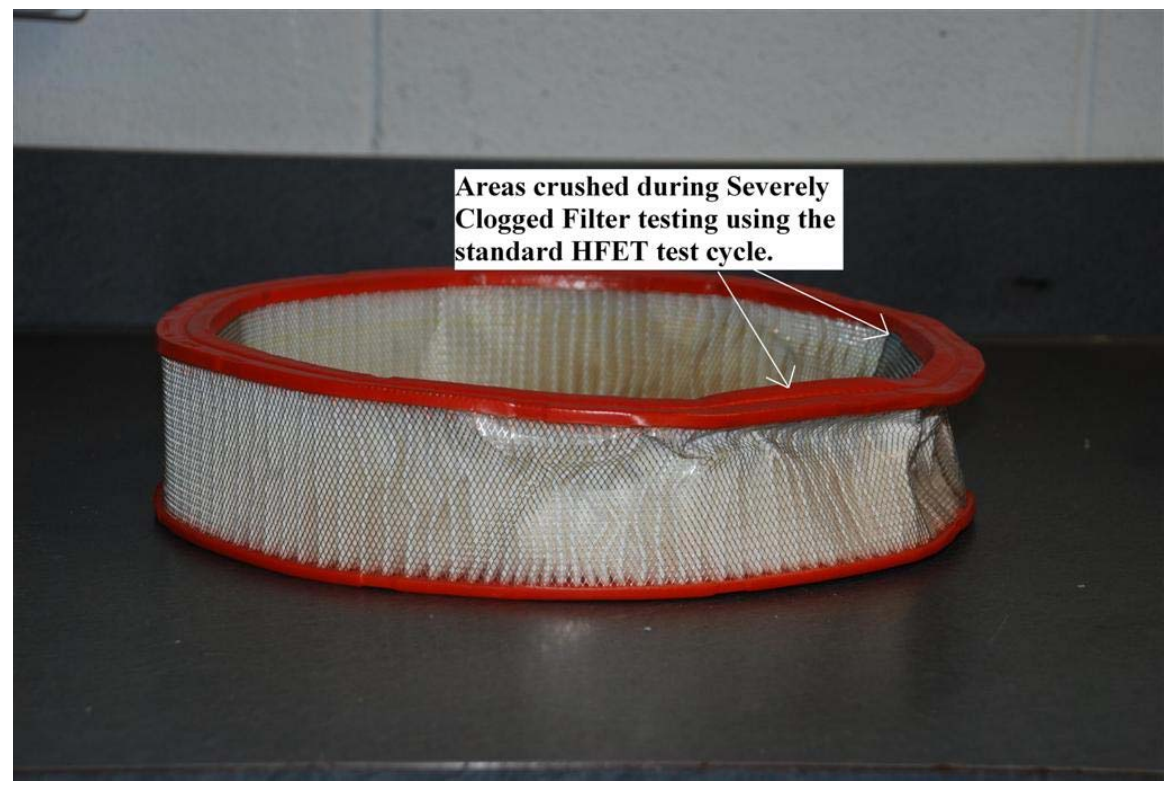

Fig. 3.18. Damaged air filter from severely clogged air filter testing, 1972 Pontiac Grandville. 
For each of the tests simulating severely clogged filters, fuel economy was calculated for the FTP and HFET cycles. However, due to the nature of the cold FTP tests that were being conducted, time constraints did not allow for the vehicle to be prepared for a cold FTP for the Severely Clogged Air Filter Test 1 setup. Each incremental increase in restriction resulted in an incremental decrease in fuel economy for the HFET, but FTP fuel economy was not affected as severely by the restriction. Figure 3.19 shows the FTP fuel economy for the different stages of testing. Figure 3.20 shows the same information for the HFET.

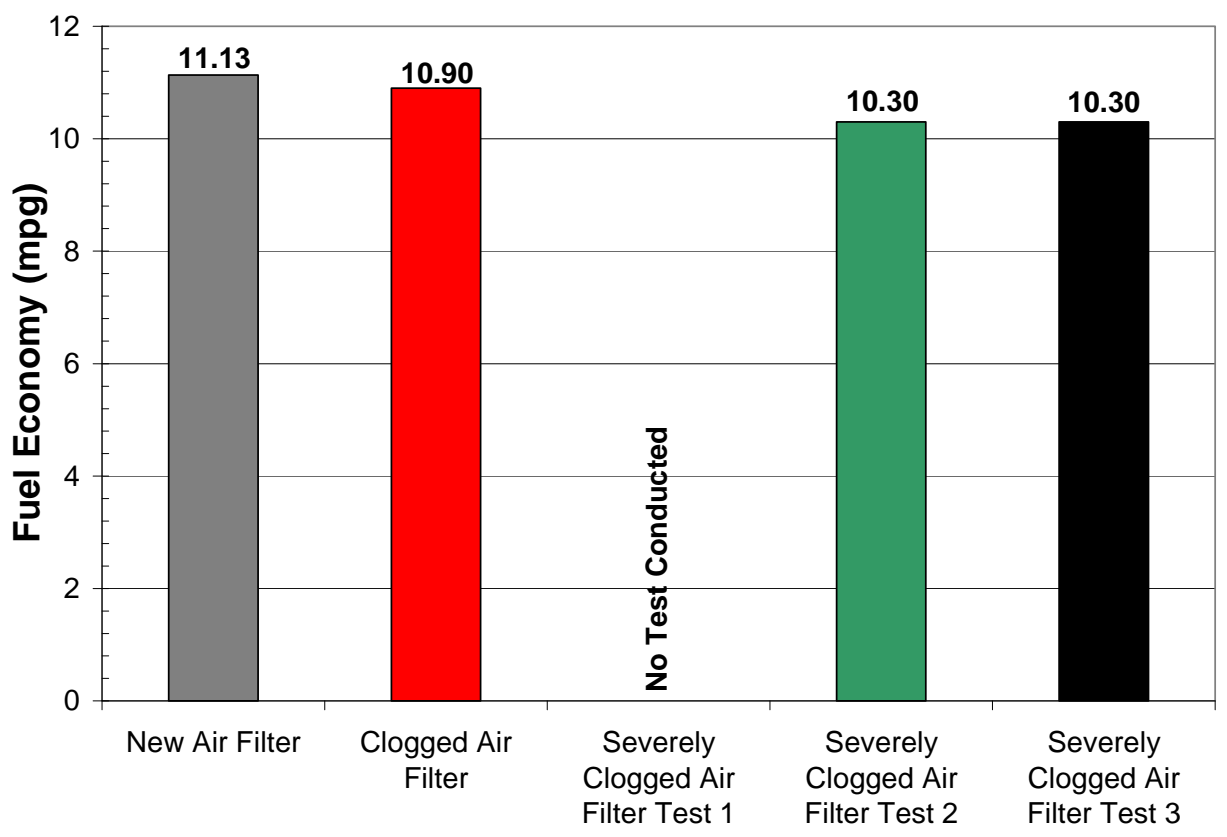

Fig. 3.19. FTP fuel economy for 1972 Pontiac Grandville.

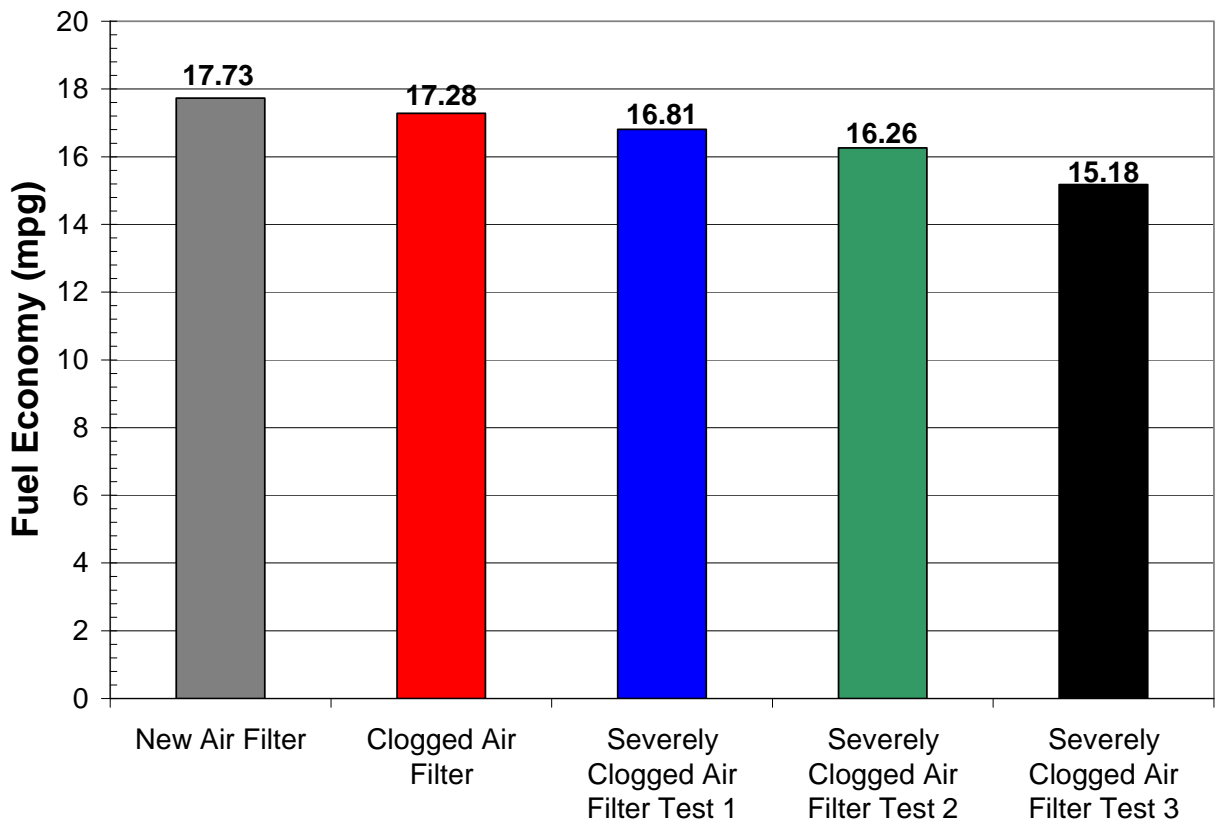

Fig. 3.20. HFET fuel economy for 1972 Pontiac Grandville. 
The initial change in fuel economy from the new air filter to the clogged air filter resulted in an FTP fuel economy decrease of $2.1 \%$. The HFET fuel economy initially decreased $2.5 \%$ from the new air filter to the clogged air filter.

For Severely Clogged Air Filter Test 1, the HFET fuel economy decreased another 2.7\% from the initial clogged air filter test (a 5.2\% decrease from the new filter case). The progression from the initial clogged filter test and the Severely Clogged Filter Test 1 were on the same day, so no FTP data are available.

For Severely Clogged Air Filter Test 2, the restriction level was increased further to obtain a greater Outlet DP resulting in an additional loss of fuel economy. Fuel economy under the FTP decreased more than 5\% from the initial clogged air filter test results and about 7.5\% from the results for the new air filter. The HFET data for Severely Clogged Air Filter Test 2 showed a fuel economy decrease of about 3\% from that in Filter Test 1 and more than 8\% from that of the new air filter.

The restriction for Severely Clogged Air Filter Test 3 was so severe that the vehicle would not accelerate past about 70-75 mph, and the driver had to consciously control the rate of change of the throttle to avoid rich misfire conditions. The HFET, like all certification tests, requires that the vehicle be operated over a defined cycle. If the vehicle is unable to meet the speed and acceleration requirements of the cycle, the test is deemed invalid. The maximum speed of the HFET cycle is about $60 \mathrm{mph}$, and further restriction would not allow the vehicle to meet the accelerations required during the cycle, invalidating the test. Therefore, this level of restriction was determined as the maximum possible restriction that could be tested. Figure 3.21 shows the average lambda (actual AFR divided by stoichiometric AFR) for the double HFETs conducted. The severely clogged air filter results in a much richer AFR (lambda $<1=$ rich, lambda $>1$ = lean). The trace file collected for the severely clogged filter test runs showed rich excursions to nearly 0.60 lambda during some of the accelerations of the cycle.

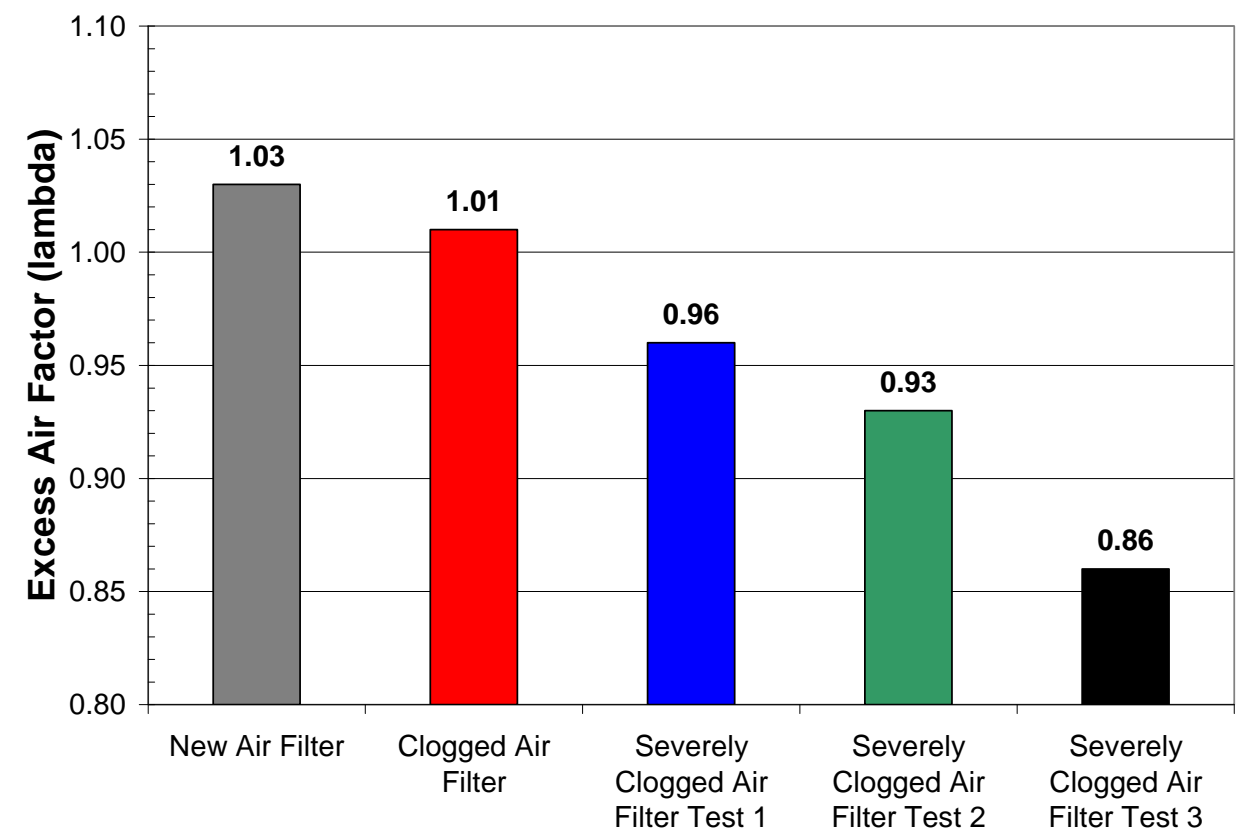

Fig. 3.21. Average double HFET lambda for 1972 Pontiac Grandville.

With the Test 3 configuration, the fuel economy did show a decrease similar to what was found in the Thornton study. ${ }^{4}$ The FTP fuel economy did not show any further decrease compared to Severely 
Clogged Air Filter Test 2, but the HFET fuel economy continued to decrease another 6\% compared to Test 2 and showed a 14.4\% decrease compared to the new air filter.

\subsubsection{Buick Lucerne}

After observing the effect of continuously increased restrictions on the fuel economy of the 1972 Pontiac, the authors decided that a greater level of restriction should also be investigated on one of the newer vehicles. Thus the 2007 Buick Lucerne was retested to explore the effects of a more severely clogged air filter on its fuel economy. The approach was to clog the air filter so severely that the vehicle would barely be able to follow the HFET cycle, similar to the final test of the Pontiac. This objective was not achievable. Before that level of restriction could be reached, the filter was pulled out of its seat in the air box due to the large pressure drop (Fig. 3.22). The average Outlet DP for the double HFET test is shown in Fig. 3.23 as Severely Clogged Air Filter Test 1. With the filter being dislodged during the test, the Severely Clogged Air Filter Test 1 data represent a test in which the air flow restriction was probably not consistent for the entire test.

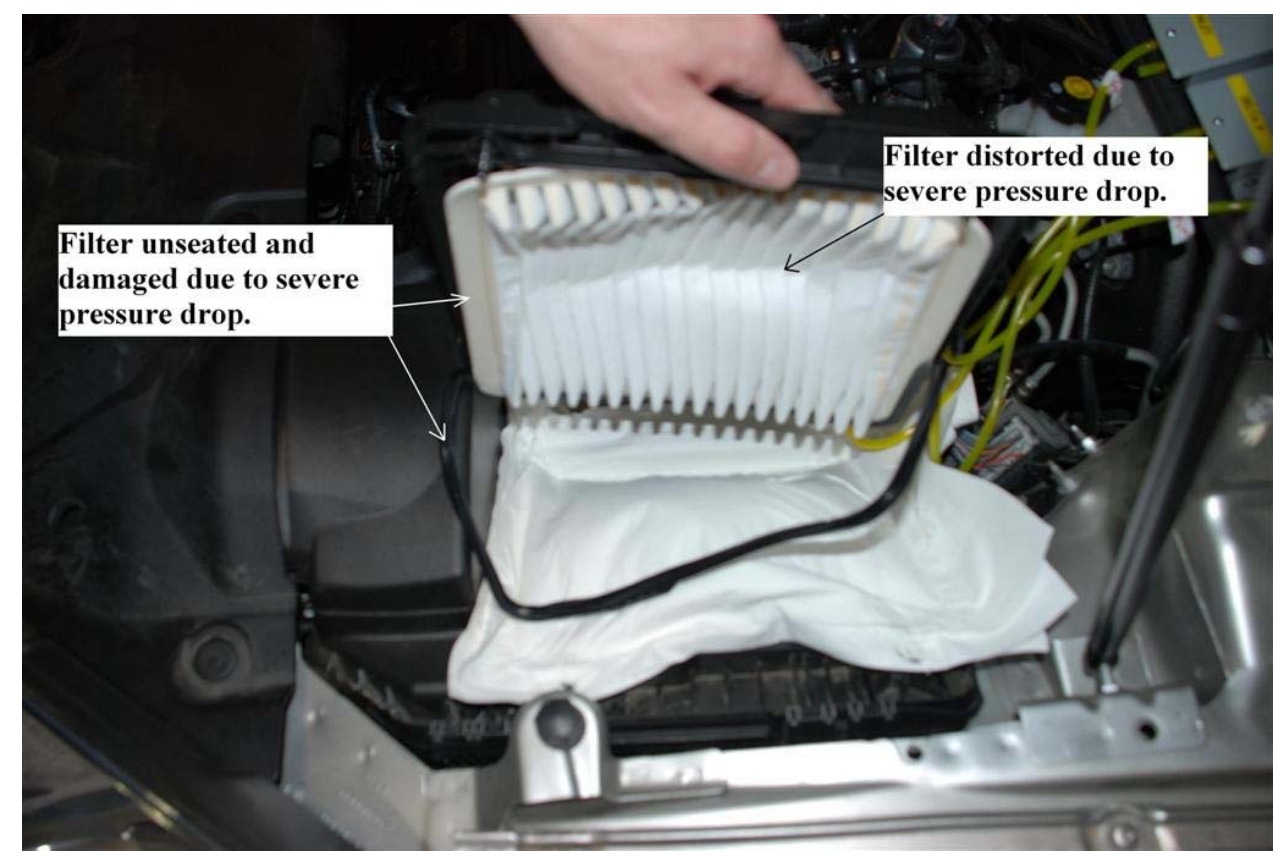

Fig. 3.22. Damaged air filter from severely clogged air filter testing, 2007 Buick Lucerne.

Data were collected for another test in which the level of restriction was higher than previously tested but not so high as to unseat the filter element. The Outlet DP related to this level of restriction is shown in Fig. 3.23 as Severely Clogged Air Filter Test 2.

The Lucerne was only tested over the double HFET cycle for these severely clogged filter simulation tests. The effects of the simulated severely clogged filter on the Lucerne's fuel economy were not significant-less than $2 \%$. These values are within the range for the series of tests that were conducted during the initial testing. Figure 3.24 shows the fuel economy of Severely Clogged Air Filter Test 1 and Test 2 versus the new air filter over the HFET cycle. The Lucerne's control system maintained a consistent AFR (lambda = 1.0) in all the tests conducted, regardless of air filter condition. 


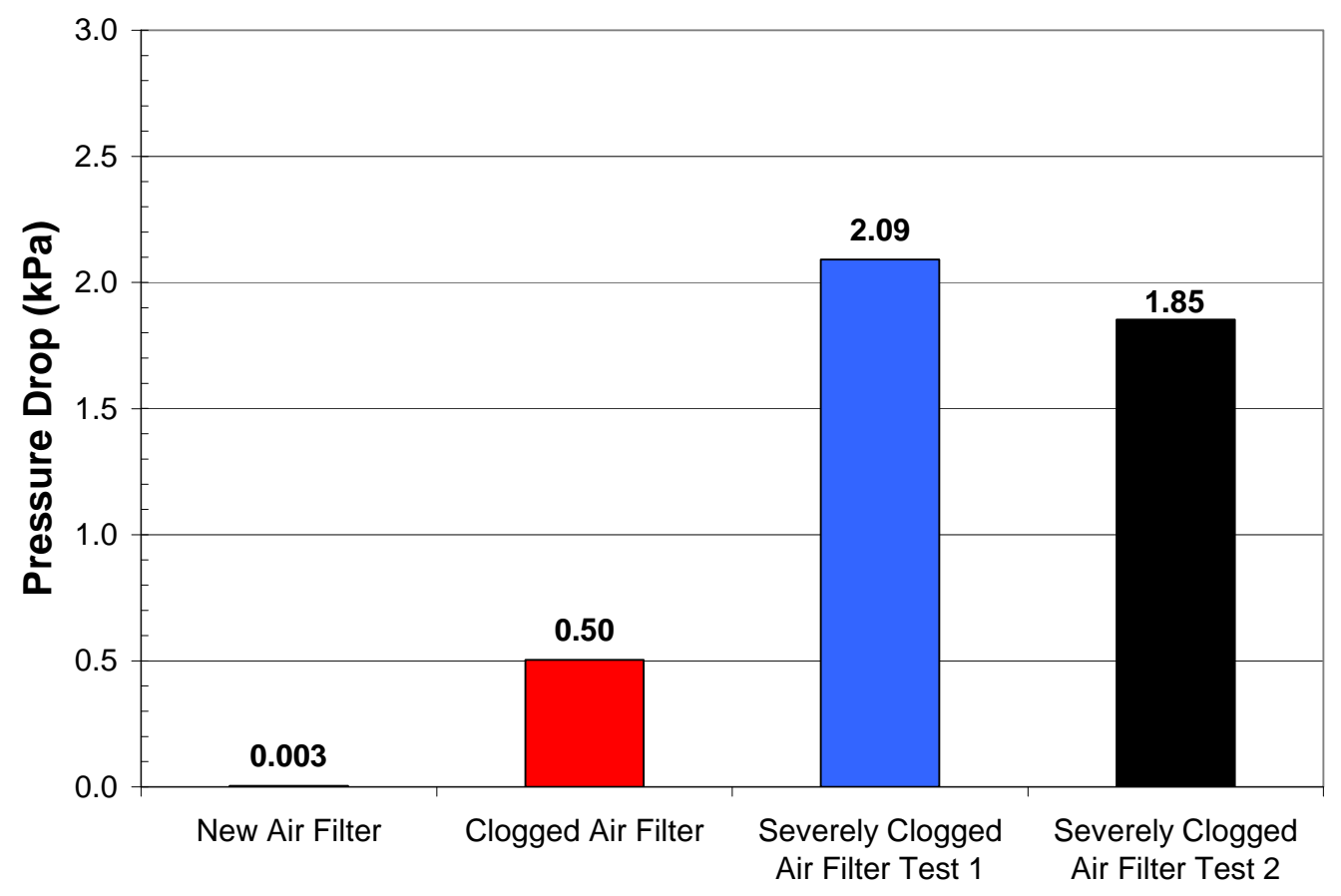

Fig. 3.23. Air filter average double HFET Outlet DP for 2007 Buick Lucerne.

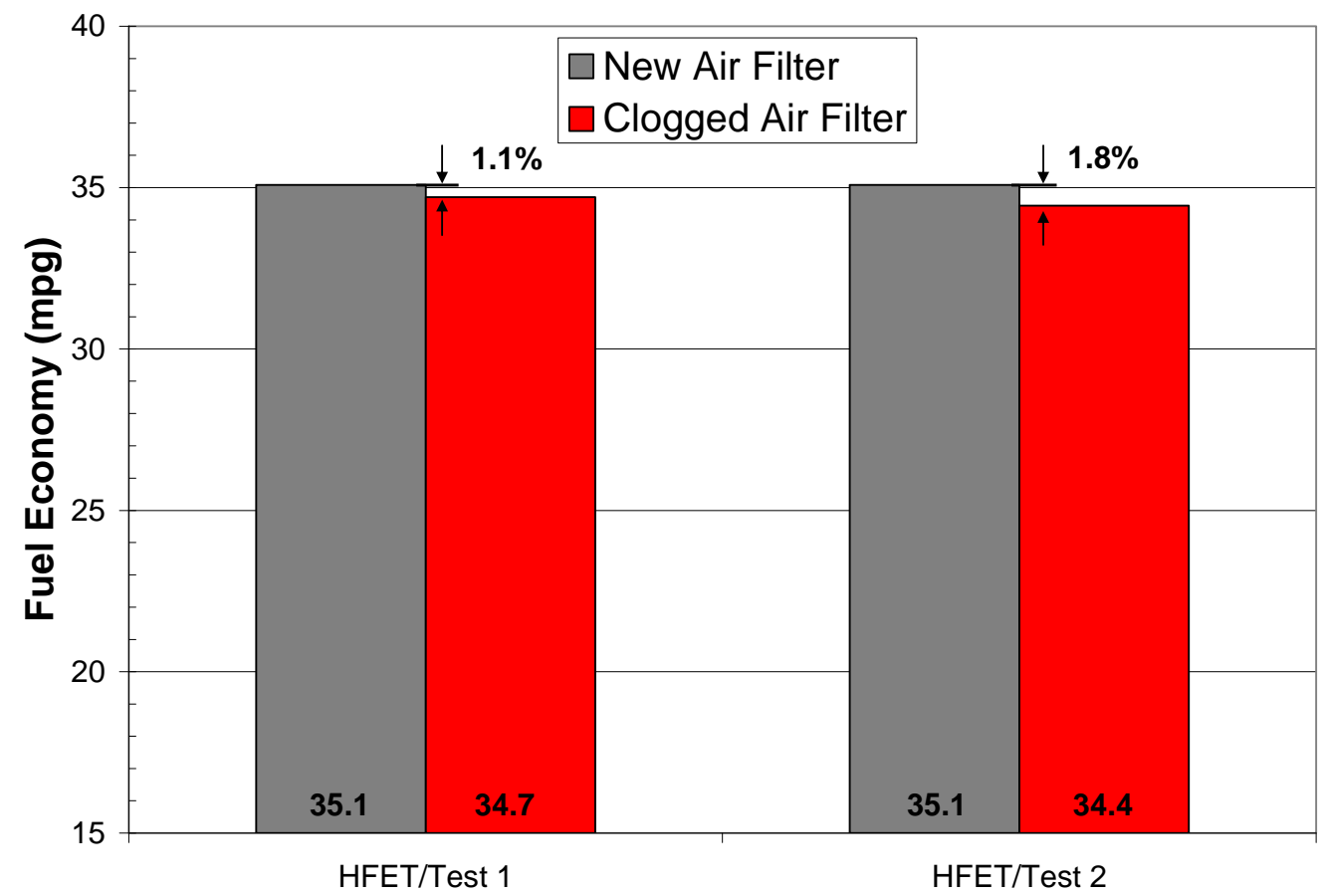

Fig. 3.24. Severely clogged air filter fuel economy for 2007 Buick Lucerne. 


\section{CONCLUSIONS AND FUTURE WORK}

\subsection{CONCLUSIONS}

The goal of this study was to explore the effects of a clogged air filter on the fuel economy of vehicles operating over prescribed test cycles. Three newer vehicles (a 2007 Buick Lucerne, a 2006 Dodge Charger, and a 2003 Toyota Camry) and an older carbureted vehicle were tested.

Results show that clogging the air filter has no significant effect on the fuel economy of the newer vehicles (all fuel injected with closed-loop control and one equipped with MDS). The engine control systems were able to maintain the desired AFR regardless of intake restrictions, and therefore fuel consumption was not increased. The carbureted engine did show a decrease in fuel economy with increasing restriction. However, the level of restriction required to cause a substantial (10-15\%) decrease in fuel economy (such as that cited in the literature ${ }^{3,4}$ ) was so severe that the vehicle was almost undrivable. Acceleration performance on all vehicles was improved with a clean air filter.

Once it was determined how severe the restriction had to be to affect the carbureted vehicle fuel economy, the 2007 Buick Lucerne was retested in a similar manner. We were not able to achieve the level of restriction that was achieved with the 1972 Pontiac with the Lucerne. The Lucerne's air filter box would not hold the filter in place under such severe conditions. (It is believed that this testing exceeded the design limits of the air box.) Tests were conducted at a lower restriction level (although still considerably more severe than the initial clogged filter testing), allowing the air filter to stay seated in the air box, and no significant change was observed in the Lucerne's fuel economy or the AFR over the HFET cycle.

Closed-loop control in modern fuel injected vehicle applications is sophisticated enough to keep a clogged air filter from affecting the vehicle fuel economy. However for older, open-loop, carbureted vehicles, a clogged air filter can affect the fuel economy. For the vehicle tested, the fuel economy with a new air filter improved as much as $14 \%$ over that with a severely clogged filter (in which the filter was so clogged that drivability was impacted). Under a more typical state of clog, the improvement with a new filter ranged from 2 to $6 \%$.

\subsection{FUTURE WORK}

Power in the modern SI engine is controlled by manipulating the manifold pressure through throttling of the intake air. The increased restriction of a clogged filter affects ultimate power but not fuel economy of modern SI engines. Any additional pumping loss due to the state of the air filter is offset by the throttle. Conventional diesel engines operate without throttles-although throttles are in use in some diesels today for active control of exhaust temperature and species, to enhance warm-up, or control exhaust gas recirculation, these throttles are full open most of the time. Because the diesel engine is unthrottled, and airflow is high even at light load, the added restriction from a clogged filter may have a measureable effect on fuel economy. Future work will investigate the effect of intake air filter state on a number of diesel vehicles. 



\section{REFERENCES}

1. U.S. Department of Energy Office of Energy Efficiency and Renewable Energy/U.S. Environmental Protection Agency, Fuel Economy Guide, DOE/EE-D325.

2. Jaroszczyk, T., J. Wake, and M. J. Connor, "Factors Affecting the Performance of Engine Air Filters,” Journal of Engineering for Gas Turbines and Power, 115, pp. 693-699 (October 1993).

3. Organization for Economic Co-operation and Development (OECD), Automobile Fuel Consumption in Actual Traffic Conditions (OECD, Paris, December 1981) pp.74-78.

4. Atkinson, J., and O. Postle, “The Effect of Vehicle Maintenance on Fuel Economy,” in D. R. Blackmore and A. Thomas, Fuel Economy of the Gasoline Engine (Shell Research Limited, Thornton Research Center, Chester, United Kingdom, 1977).

5. Bugli, Neville J., Automotive Engine Air Cleaners-Performance Trends, Society of Automotive Engineers Technical Series 2001-01-1365.

6. Grafe, Timothy, et al., "Nanofibers in Filtration Applications in Transportation,” International Conference and Exposition of the INDA (Association of the Nonwovens Fabric Industry), Chicago, Illinois, December 3-5, 2001.

7. Patil, A. S., V. G. Halbe, and K.C. Vora, A System Approach to Automotive Air Intake System Development, Society of Automotive Engineers Technical Series 2005-26-011.

8. Zemaitis, Wally, “Stacked Panel Filter for Engine Air Intake Systems,” International Congress and Exposition, Detroit, Michigan, February 23-36, 1998, Society of Automotive Engineers Technical Series 980868.

9. Bugli, Neville J., and Gregory S. Green, "Performance and Benefits of Zero Maintenance Air Induction Systems,” 2005 SAE World Congress, Detroit, Michigan, April 11-14, 2005, Society of Automotive Engineers Technical Series 2005-01-1139.

10. Bugli, Neville J., Scott Dobert, and Scott Flora, “Investigating Cleaning Procedures for OEM Engine Air Intake Filters,” 2007 World Congress, Detroit, Michigan, April 16-19, 2007, Society of Automotive Engineers Technical Series 2007-01-1431.

11. Thiyagarajan, P, and V. Ganesan, "Study of Flow through Air Filter for Off Highway Vehicle-A Preliminary CFD Approach,” Society of Automotive Engineers Technical Series 2005-26-339.

12. West, Brian, et al., Effects of Intermediate Ethanol Blends on Legacy Vehicles and Small Non-Road Engines, Report 1, ORNL/TM-2008/117, October 2008. 
